\title{
VOLTZIALES Y PINALES (= CONIFERALES) DE LA FORMACIÓN CORTADERITA (TRIÁSICO MEDIO), ARGENTINA, Y SU IMPLICANCIA EN LA RECONSTRUCCIÓN DE LAS CONÍFERAS TRIÁSICAS
}

\author{
JOSEFINA BODNAR \\ División Paleobotánica, Facultad de Ciencias Naturales y Museo, CONICET, Paseo del Bosque s/n, B1900FWA, \\ La Plata, Buenos Aires, Argentina.jbodnar@fcnym.unlp.edu.ar
}

DANIELA PAULA RUIZ

División Paleobotánica, Museo Argentino de Ciencias Naturales "Bernardino Rivadavia”, CONICET, Av. Ángel Gallardo 470, C1405DJR, Ciudad Autónoma de Buenos Aires, Argentina.ruizdaniela8@gmail.com

\author{
ANALÍA EMILIA ARTABE \\ División Paleobotánica, Facultad de Ciencias Naturales y Museo, CONICET, Paseo del Bosque s/n, B1900FWA, \\ La Plata, Buenos Aires, Argentina. aartabe@fcnym.unlp.edu.ar
}

EDUARDO MANUEL MOREL

División Paleobotánica, Facultad de Ciencias Naturales y Museo, CIC, Paseo del Bosque s/n, B1900FWA, La Plata, Buenos Aires, Argentina.emorel@fcnym.unlp.edu.ar

\section{DANIEL GANUZA}

División Paleobotánica, Facultad de Ciencias Naturales y Museo, Paseo del Bosque s/n, B1900FWA, La Plata, Buenos Aires, Argentina.dganuza@fcnym.unlp.edu.ar

\begin{abstract}
VOLTZIALES AND PINALES (= CONIFERALES) FROM CORTADERITA FORMATION (MIDDLE TRIASSIC), ARGENTINA, AND THEIR IMPLICATION IN THE RECONSTRUCTION OF TRIASSIC CONIFERS. In this work, fossil wood, leaves, and branches designated to the subclass Pinidae (Voltziales and Pinales) are described from Cortaderita Formation (Middle Triassic). Fossil materials were collected at Cortaderita and La Tinta creeks, at Barreal area from Barreal-Calingasta basin, Pre-Andean region of San Juan, Argentina. Leaves corresponding to three species of Heidiphyllum (order Voltziales), leafy twigs assigned to Elatocladus planus (Pinales) and permineralized trunks and branches ascribed to Cupressinoxylon zamunerae sp. nov. (Pinales), were recognized. The last two species exhibit characters that allow designating them to family Cupressaceae sensu lato. At the same time, it is demonstrated that they belong to the same plant, which is named as the new species of Cupressinoxylon here described. This reconstruction is based on kindred reinforcement and mutual occurrence criteria, besides morphological and anatomical characters. Thus, Cupressinoxylon zamunerae sp. nov. is interpreted as a tree $13 \mathrm{~m}$ tall, highly branched, with penultimate order shoots with scale-like leaves and last order shoots with alternate, sessile, single-veined, linear to acicular leaves distributed helically. These records confirm the presence of Cupressaceae sensu lato since the Triassic in Gondwana.
\end{abstract}

Key words: Barreal-Calingasta, Sorocayense Group, Voltziaceae, Cupressaceae sensu lato.

RESUMO - Neste trabalho são descritos lenhos, folhas e ramos para a subclasse Pinidae (Voltziales e Pinales) da Formação Cortaderita (Triássico Médio). Os materiais foram encontrados nas quebradas La Cortaderita e La Tinta, na área de Barreal, bacia de Barreal-Calingasta, precordillera de San Juan, Argentina. Foram reconhecidas folhas correspondentes a três espécies do gênero Heidiphyllum (Voltziales), ramos folhosos atribuídos a Elatocladus planus (Pinales) e lenhos permineralizados designados como Cupressinoxylon zamunerae sp. nov. (Pinales). As duas últimas espécies têm características que permitem atribuí-los para a família Cupressaceae sensu lato. Por isso, neste estudo mostra-se que correspondem a mesma entidade biológica. Assim é descrito com o nome da nova espécie de Cupressinoxylon. Esta reconstrução é baseada em critérios de reforço mútuo e de ocorrência afins, além de características morfológicas e anatômicas. Desta forma, Cupressinoxylon zamunerae sp. nov. é interpretada como uma árvore de aproximadamente $13 \mathrm{~m}$ de altura, muito ramificada, com ramos da penúltima ordem com folhas escamiformes, e ramos de última ordem alternados, com folhas sésseis, uninerveadas, lineares a aciculares distribuídas helicoidalmente. Esses registros confirmam a presença de Cupressaceae sensu lato, desde o Triássico no Gondwana desde o Triássico.

Palavras-chave: Barreal-Calingasta, Grupo Sorocayense, Voltziaceae, Cupressaceae sensu lato. 


\section{INTRODUCCIÓN}

Las comunidades arbóreas triásicas del Sudoeste de Gondwana estaban dominadas por Corystospermales ("Pteridospermas" o helechos con semilla) dejando a las coníferas un rol muy subordinado, que recién sería más importante a partir del Triásico Superior y el Jurásico Inferior y Medio, precisamente gracias a la declinación de las corystospermas (Artabe et al., 2007).

El registro triásico de las coníferas en Sudamérica incluye leños permineralizados, impresiones-compresiones de hojas, ramas foliosas y conos, y granos de polen; asignados a los órdenes Voltziales y Pinales (familias Cheirolepidiaceae, Podocarpaceae, Araucariaceae, Cupressaceae sensu lato) (Zamuner et al., 2001; Artabe et al., 2003).

Actualmente se conocen para el Sistema Triásico argentino las siguientes especies de leños asignadas a las coníferas: Araucariaceae, Agathoxylon protoaraucana (Brea) Gnaedinger \& Herbst, 2009, Agathoxylon lamaibandianus Crisafulli \& Herbst, 2011, Agathoxylon dallonii (Boureau) Crisafulli \& Herbst, 2010, Agathoxylon amraparense (Sah \& Jain) Crisafulli \& Herbst, 2011; Podocarpaceae, Podocarpoxylon tikiense Ram-Awatar \& Rajanikanth, 2007, Podocarpoxylon indicum (Bhardwaj) Bose \& Maheshwari, 1974, Podocarpoxylon paralatifolium Vozenin-Serra \& Grant-Mackie, 1996; Cupressaceae s.l., Protojuniperoxylon ischigualastense Bonetti emend. Bodnar \& Artabe, 2007; y cuatro especies de familia incierta: Protocircoporoxylon marianaensis Zamuner \& Artabe, 1994, Agathoxylon (= Araucarioxylon) sp. A. (Zamuner, 1992), Protophyllocladoxylon sp. (Crisafulli \& Herbst, 2011), Prototaxoxylon intertrappeum Prakash \& Srivastava, 1961 y Taxaceoxylon sp. (Caminos et al., 1995). Aunque las dos últimas fueron asignadas a las Taxaceae (Zamuner et al., 2001; Crisafulli \& Herbst, 2010), los caracteres en los que se basa esa afirmación probablemente sean productos de la degradación de la pared de las células xilemáticas o que correspondan a leño de compresión.

Por otra parte, también son abundantes los registros de formas foliares de coníferas: Heidiphyllum elongatum (Morris) Retallack, 1981, entre las Voltziales; y Elatocladus planus (Feistmantel) Seward, 1919, E. australis Frenguelli, 1944, Rissikia media (Tenison Woods) Townrow, 1967 y Pagiophyllum sp., entre las Pinales (Artabe et al., 2007). En cuanto a las estructuras reproductivas, son frecuentes los conos megasporangiados de las Voltziales: Telemachus lignosus Retallack, 1981 y T. elongatus Anderson, 1978, Dordrechtites sp. (Spalletti et al., 1991; Arce \& Lutz, 2010; Morel et al., 2011).

En el registro palinológico, existen numerosas citas acerca de granos de polen afines a las coníferas: Triadispora, Brachysaccus, Podocarpidites, Lunatisporites, Striatoabieites, Araucariacites, entre otros (Zamuner et al., 2001; Zavattieri \& Rojo, 2005).

Excepto por la asociación Heidiphyllum/Telemachus, todos estos restos no han sido vinculados entre sí en reconstrucciones. No obstante, esta entidad no se ha relacionado con alguno de los leños registrados en la Argentina. En general, se acepta que las Voltziales y las Pinales compartían el mismo hábito arbóreo, profusamente ramificado (Taylor et al., 2009). Anatómicamente, el xilema secundario de las Voltziales triásicas y de las Pinales podría presentar similitudes. De hecho, en otras regiones del Gondwana, se ha sugerido una reconstrucción en la que se vincula a Heidiphyllum/ Telemachus con troncos permineralizados, de características semejantes a los leños de las podocarpáceas (Axsmith et al., 1998; Escapa et al., 2010; Bomfleur et al., 2013).

La necesidad de avanzar en el conocimiento de las reconstrucciones de las coníferas triásicas, radica en que es en dicho período donde se produce el origen y la diversificación de los clados modernos, puesto que para el Jurásico ya encontramos representantes de cada familia (excepto por las Pinaceae) bien diferenciados (Stewart \& Rothwell, 1993). A la hora de vincular los diferentes órganos de coníferas triásicas en una reconstrucción, existen varias dificultades, e.g. el registro de los conos micro y megasporangiados es escaso o de difícil interpretación y los leños de corystospermas en estado disperso son muy semejantes anatómicamente a los de las coníferas. La alta diversidad de leños permineralizados asignados a Pinales en el Sistema Triásico de la Argentina, en comparación con la ausencia de conos micro y/o megasporangiados de Pinales, nos permite deducir que: (i) algunos ejemplares podrían corresponder al grupo dominante de los bosques triásicos, i.e. Corystospermales; (ii) ciertas formas deberían pertenecer a la voltzial Heidiphyllum/Telemachus; (iii) diferencias en la preservación han permitido la fosilización de leños de Pinales pero no así sus estructuras reproductivas.

Para resolver algunas de estos interrogantes, los registros florísticos triásicos de la Formación Cortaderita (Groeber \& Stipanicic, 1953), Grupo Sorocayense, Cuenca de BarrealCalingasta, San Juan, centro-oeste de la Argentina (Figura 1) presentan una gran ventaja, por la continuidad vertical y horizontal de los estratos plantíferos, la gran diversidad taxonómica y de condiciones tafonómicas, y la presencia de una serie de bosques fosilizados in situ correspondiendo a tafocenosis autóctonas (Artabe et al., 2001; Bodnar, 2010).

Para la Formación Cortaderita, la primera cita de un leño fósil de conífera corresponde a Menéndez (1956) quien erigió la especie Protophyllocladoxylon cortaderitaense sobre la base de material encontrado en la sección superior de la unidad, en la localidad de Quebrada de la Tinta. Posteriormente, Lutz \& Herbst (1992) describieron troncos de una corystosperma, hallados en la sección inferior de la Formación Cortaderita, en la Quebrada homónima, y los asignaron a una nueva especie del género Rhexoxylon $\mathrm{sp}$. En años recientes, Bodnar (2008) sinonimizó los dos taxones como Rhexoxylon cortaderitaense (orden Corystospermales, familia Corystospermaceae). Por lo tanto, hasta el momento, la xiloflora de estas tafocenosis estaba compuesta sólo por corystospermas.

Con respecto a los restos de hojas de coníferas, se habían citado para la Formación Cortaderita a Elatocladus sp. (Bonetti, 1963). Desafortunadamente, hasta el momento no se 


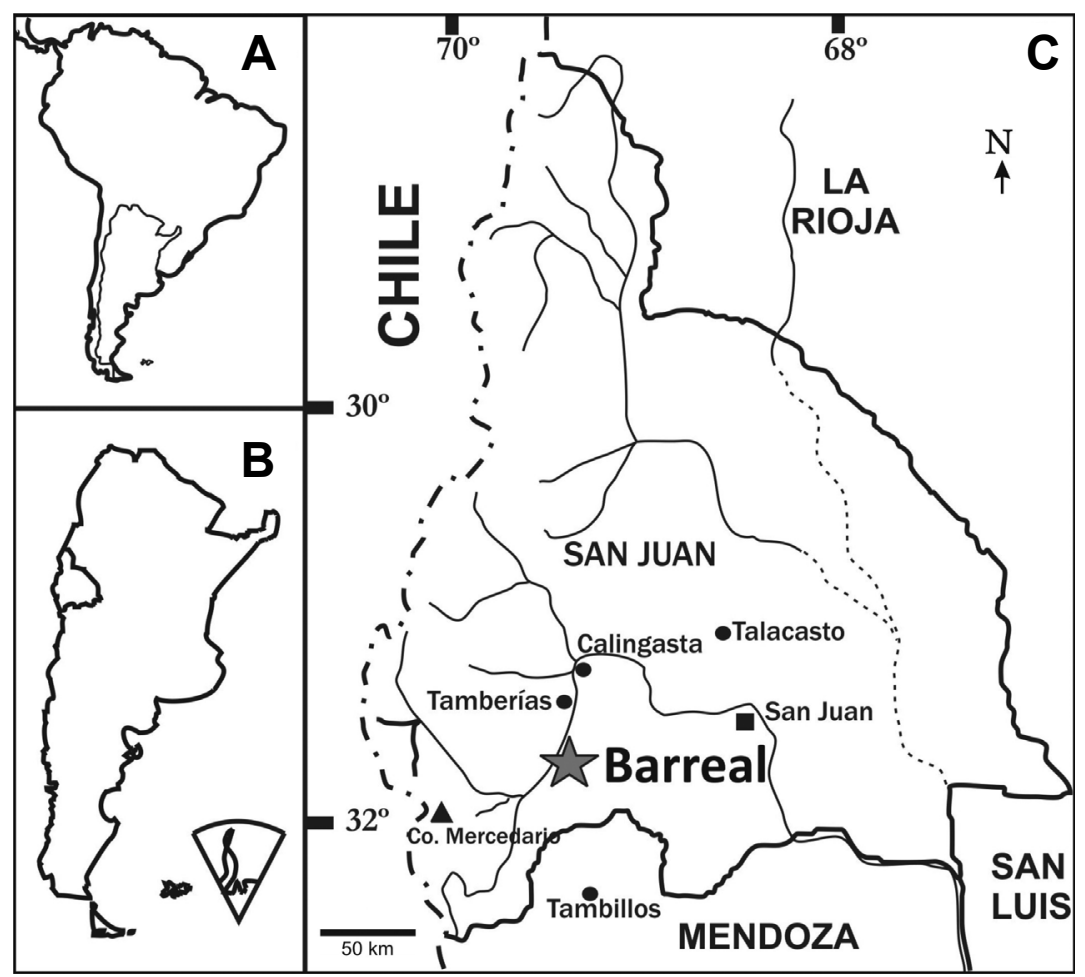

Figura 1. Mapa de ubicación del área de Barreal, Provincia de San Juan, Argentina. A, mapa de Sudamérica mostrando la ubicación de Argentina; B, mapa de Argentina, indicando la localización de la Provincia de San Juan; C, mapa de la Provincia de San Juan, donde se muestra la ubicación del área de Barreal.

Figure 1. Location map of Barreal area, San Juan Province, Argentina. A, geographical map of South America showing the location of Argentina; B, geographical map of Argentina showing the location of San Juan Province; C, geographical map of San Juan Province showing Barreal area.

ha encontrado muestras fértiles en las marchas palinológicas realizadas (Volkheimer, pers. com.).

En este trabajo se presenta el hallazgo de leños, hojas y ramas asignables a la subclase Pinidae (órdenes Voltziales y Pinales), provenientes de la Formación Cortaderita, se discute su afinidad sistemática, y las posibles reconstrucciones de las plantas.

\section{MARCO GEOLÓGICO}

El conjunto sedimentario triásico que aflora en la Precordillera occidental sanjuanina está localizado en dos sectores: Rincón Blanco (en la Sierra de Tontal) y BarrealCalingasta (en el valle del Río de Los Patos) (Figura 2). Las sedimentitas de Barreal-Calingasta asoman principalmente en dos áreas: en las cercanías de la ciudad de Barreal y en Hilario.

Se ha interpretado que los depósitos del área de BarrealCalingasta junto a los de Rincón Blanco representan el registro de un hemigraben con fuerte asimetría (López Gamundí, 1994; Barredo \& Ramos, 1997), cuya rampa está ubicada hacia el Oeste y su margen fallado, con marcada subsidencia, hacia el Sudeste. De acuerdo a los autores, las sedimentitas del sector de Barreal-Calingasta fueron acumuladas en la rampa del hemigraben, esto es, el margen estable poco disturbado tectónicamente, y las del área de Rincón Blanco, en el margen tectónicamente activo.
Las sucesiones triásicas de Barreal-Calingasta afloran en una ancha banda al Este de las localidades de Hilario, Sorocayense y Barreal, y poseen un escaso relieve relativo con baja tasa de subsidencia (Stipanicic, 1972; López Gamundí, 1994). Se componen de diversas facies sedimentarias silicoclásticas, con fuerte afinidad volcánica, interpretadas como sistemas depositacionales de: abanico y cono aluvial, fluvial entrelazado (gravoso y arenoso), fluvial efímero, fluvial meandroso de carga mixta o de alta sinuosidad, planicies con sedimentación piroclástica, lacustres hidrológicamente abiertos (holomícticos y meromócticos) y deltaicos de influencia fluvial (Spalletti, 2001a).

Mésigos (1953) introdujo el nombre de Grupo Sorocayense para las rocas triásicas que afloran al Este de Barreal. Las unidades estratigráficas de esta cuenca son, de base a techo: Formación Barreal, Formación Cortaderita y Formación Cepeda (Groeber \& Stipanicic, 1953), para el sector de Barreal (Figura 3), y Formación Agua de los Pajaritos, Formación El Alcázar y Formación Hilario (Groeber \& Stipanicic, 1953), para el sector de Hilario.

En la región de Barreal, la Formación Cortaderita ha sido de interés para numerosos investigadores, debido tanto a la accesibilidad y calidad de sus afloramientos, como a su riqueza fosilífera (e.g. Du Toit, 1927; Cuerda, 1945; Stipanicic, 1972, 1979, 1983; Groeber \& Stipanicic, 1953; Menéndez, 1956; Bonetti, 1963, 1968, 1972; Lutz \& Herbst, 


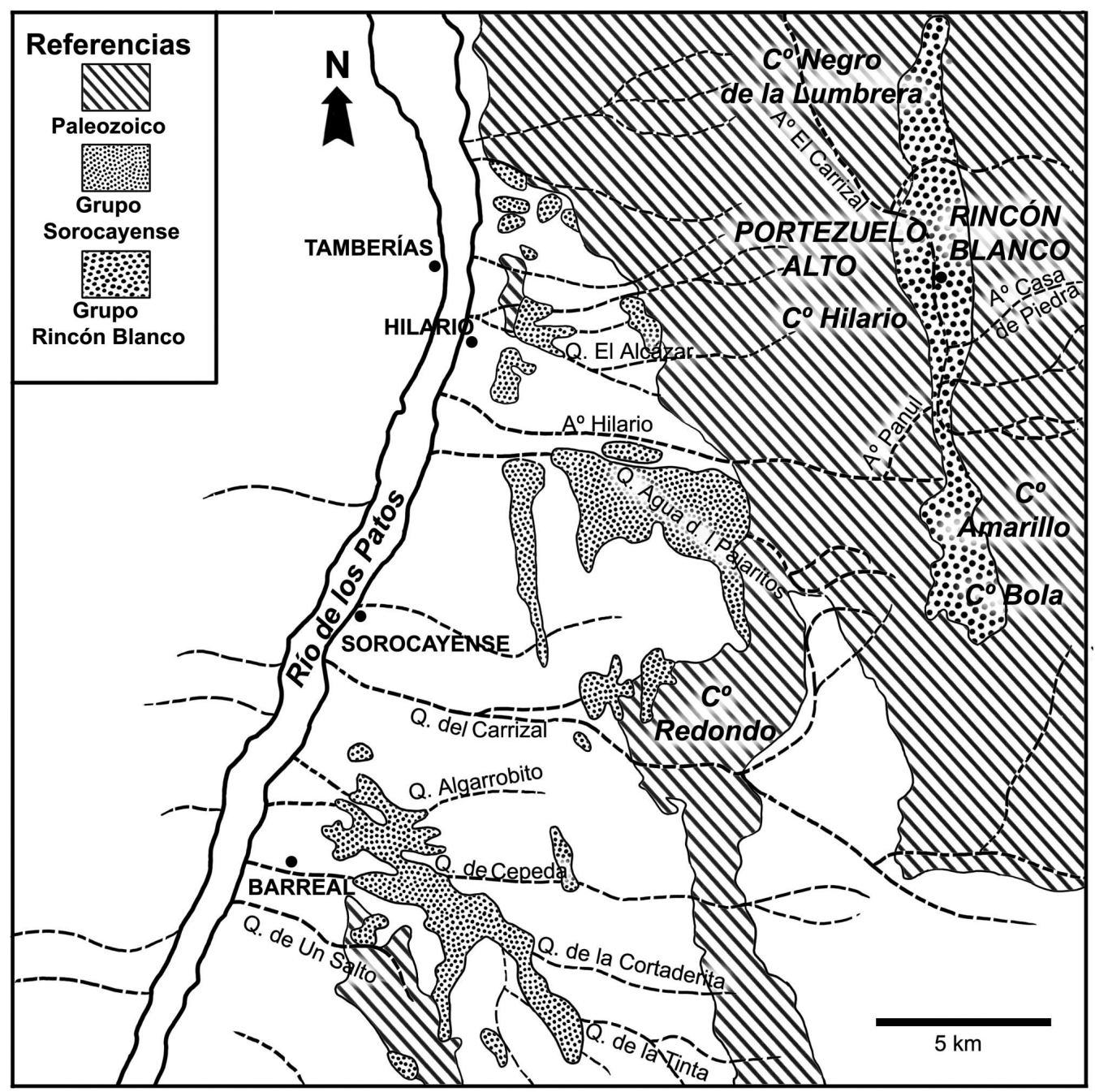

Figura 2. Mapa geológico del depocentro de Barreal-Calingasta y Rincón Blanco.

Figure 2. Geologic map of Barreal and Rincón Blanco depocenter.

1992; Artabe et al., 2001; Spalletti, 2001a; Zamuner et al., 1999, Bodnar, 2008). Los principales afloramientos de esta unidad se localizan en una serie de quebradas que, de Sur a Norte, reciben el nombre de Un Salto, la Tinta, Cortaderita y Cepeda (Figura 2).

Estratigráficamente, la Formación Cortaderita ha sido subdivida en dos secciones: una Inferior Grisy otra Superior Rosada, debido a sus claras diferencias litológicas (Artabe et al., 2001; Spalletti, 2001a) (Figura 3). La Sección Inferior está dominada por limolitas y areniscas limosas grises bentoníticas, masivas, intercaladas con canales de areniscas amarillentas y mantos de bentonitas verdosas (Bodnar, 2010). Se ha sido inferido que esta sucesión fue depositada por un sistema lacustre de tipo meromíctico (Spalletti, 2001a) o por sistemas fluviales meandrosos (Bodnar, 2010). En la Sección Superior rosada predominan las areniscas finas a gruesas y sabulíticas rosadas y rojizas, laminadas y ondulíticas (Bodnar, 2010). Estas sedimentitas han sido interpretadas como un sistema fluvial entrelazado arenosogravoso (Spalletti, 2001a).
Sobre la base del contenido paleoflorístico y la correlación con otras unidades, la edad reconocida para la sección Inferior de la Formación Cortaderita es Triásico Medio (Morel et al., 2001; Spalletti, 2001b).

\section{NIVELES FOSILÍFEROS}

Stipanicic \& Bonetti (in Groeber \& Stipanicic, 1953), realizaron el primer ordenamiento preciso del contenido paleobotánico del Grupo Sorocayense en el área de Barreal, estableciendo tres niveles fosilíferos $(=\mathbf{N F})$ : NFI, en la parte superior de la Formación Barreal, NFII en la Sección Inferior de la Formación Cortaderita y NFIII en la Sección Superior de esta última. Posteriormente, Bonetti $(1963,1968,1972)$ estudió en detalle la composición, posición estratigráfica y puntos de afloramiento de dichos niveles fosilíferos. De acuerdo a esta autora, el NFI afloraba en las quebradas de la Cortaderita (punto 11) y de la Tinta (punto 12); el NFII, en la quebrada de Un Salto (puntos 20 y 21), y el NFIII, en las quebradas de la Cortaderita (punto 30) y de la Tinta (puntos 31, 32, 34, 35 y 36). 


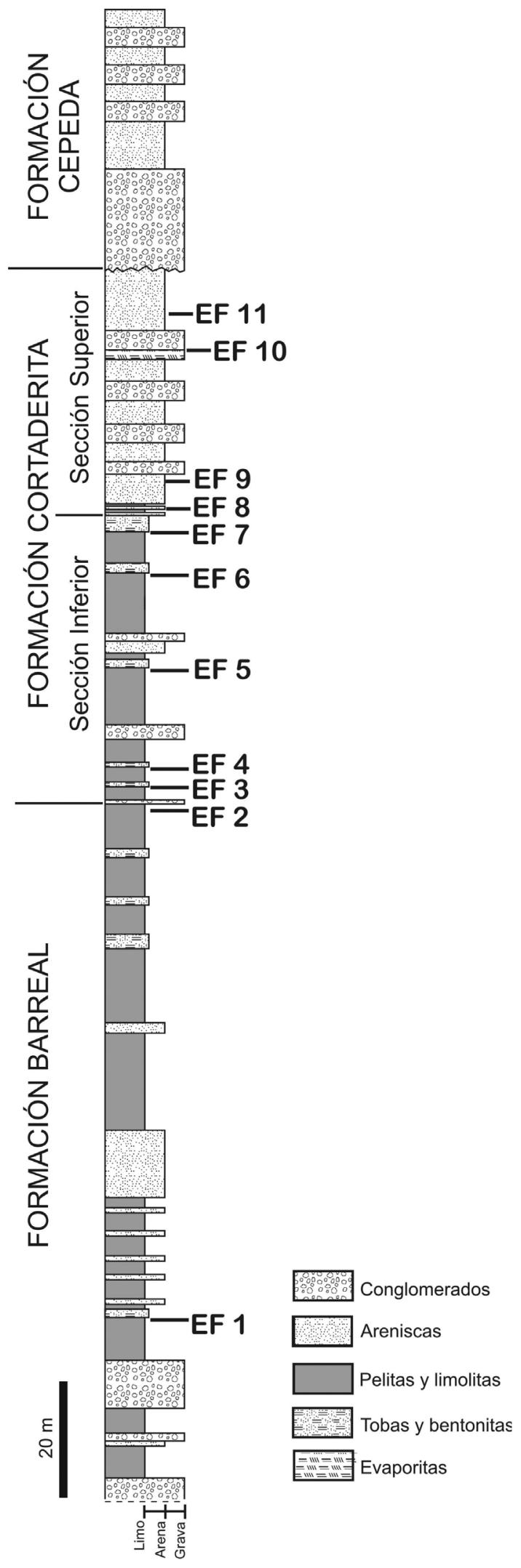

Figura 3. Perfil sedimentológico general del Grupo Sorocayense en el área de Barreal, con la posición estratigráfica de los estratos fosilíferos reconocidos (EF).

Figure 3. General sedimentary log of Sorocayense Group, with the stratigraphic position of the recognized fossiliferous strata (EF).
Zamuner et al. (1999) y Artabe et al. (2001) presentaron una nueva propuesta acerca de los niveles plantíferos de BarrealCalingasta, establecieron las correspondencias con los niveles de Bonetti (1963), y agregaron nuevos niveles y nuevos taxones hallados. En la Formación Cortaderita reconocieron dos estratos fosilíferos: uno en la Sección Inferior correlacionable al NFI en el punto 12 y al NFII de Bonetti (1963), y caracterizado por troncos in situ y raigones que atravesaban tres niveles con impresiones-compresiones; y otro en la Sección Superior, equivalente al NFIII de Bonetti (1963).

En este trabajo se reconoce un total de once estratos fosilíferos (EF) en las formaciones Barreal y Cortaderita, de los cuales dos están localizados en la primera unidad, y nueve se ubican en la segunda unidad formacional (Figura 3).

\section{MATERIAL Y MÉTODOS}

Los materiales estudiados corresponden a impresionescompresiones de hojas y ramas foliosas y permineralizaciones de troncos y ejes de menor porte. Han sido hallados en limolitas grises bentoníticas y bentonitas bioturbadas (Figura 3), de la Sección Inferior gris de la Formación Cortaderita (Spalletti, 2001a) en las quebradas de la Cortaderita y La Tinta, a $6 \mathrm{~km}$ al Este de la ciudad de Barreal, en la cuenca de Barreal-Calingasta, Precordillera Sanjuanina, Argentina (Figura 1). Todos los fósiles aquí estudiados provienen de los EF5 y EF6, según el esquema de presentado en este trabajo.

El material fósil recolectado fue preparado según el tipo de fosilización. Las impresiones-compresiones fueron limpiadas mecánicamente con cinceles, agujas y lápiz neumático. Para ilustrar los ejemplares, se los fotografió con cámara digital Canon Powershot $\mathrm{S} 40 \mathrm{y}$ luz rasante. Los ejemplares permineralizados tienen una composición silícea y una calidad de preservación regular. Se obtuvieron superficies pulidas de los tres planos de corte básicos usados en histología (transversal, longitudinal radial y longitudinal tangencial). Las superficies así terminadas se examinaron con luz incidente por medio de la utilización de lupa binocular Nikon e ilustrados mediante fotografías con sistema Leica DC 150, y cámaras digitales Canon Powershot S40 y Nikon Coolpix P500. La histología en detalle se estudió mediante la realización de cortes delgados petrográficos, que fueron estudiados con microscopio óptico Leitz Wetzlar Ortholux y fotografiados con sistema Leica DC 150 y cámara digital Canon Powershot S40.

Los materiales megascópicos y microscópicos están depositados en la Colección Paleobotánica del Museo de Ciencias Naturales de San Juan, bajo las siglas PBSJ/ PBSJPm.

En la descripción de las hojas (impresiones-compresiones) se aplicaron los términos brindados por el diccionario de botánica de Font Quer $(1963,1982)$. Para el estudio de los troncos (permineralizaciones) se empleó la terminología de los glosarios de anatomía de maderas (Boureau, 1956; Fahn, 1990; IAWA, 2004), y el atlas de anatomía de maderas de Greguss $(1955,1968)$. La medida de los distintos elementos morfológicos y anatómicos se obtuvo en base a un registro de 30 mediciones. Para los materiales megascópicos, se 
utilizaron reglas y cintas métricas para medir sobre el fósil, o mediante reglillas de la lupa binocular. Para los cortes petrográficos, se utilizaron las reglillas del microscopio.

En el tratamiento nomenclatural se utilizaron: International Code of Botanical Nomenclature (Melbourne Code, McNeill et al., 2012), Phylogenetic Code of Biological Nomenclature (Cantino \& de Queiroz, 2006; Cantino et al., 2007) e Indices Nominum Supragenericorum Plantarum Vascularium (Reveal, 2012). Se siguió el criterio sistemático de Christenhusz et al. (2011) a nivel de subclase. Sin embargo, a nivel de orden y familia, se aplicó una clasificación más clásica, basada en las propuestas de Eckenwalder (1976, 2009), Stewart \& Rothwell (1993) y Anderson \& Anderson (2003).

Para la reconstrucción de las plantas, se vincularon las diferentes partes de acuerdo a los criterios de Anderson \& Anderson (1985). Se analizó en detalle la anatomía y morfología de los órganos preservados para inferir el hábito de vida. Para la estimación de la altura de los árboles, se usaron las ecuaciones del Niklas (1994a,b,c) que utilizan el diámetro de los troncos para calcular la altura crítica $\left(\mathrm{H}_{\text {crit }}\right) \mathrm{y}$ la altura estimada $\left(\mathrm{H}_{\mathrm{est}}\right)$.

\section{SISTEMÁTICA PALEOBOTÁNICA}

\author{
Subclase PINIDAE Cronquist, \\ Takhtajan \& Zimmermann, 1966 \\ Orden VOLTZIALES sensu Rothwell, Mapes \& \\ Hernandez-Castillo, 2005 \\ Familia VOLTZIACEAE Arnold, 1947
}

Heidiphyllum Retallack, 1981

Especie tipo. Heidiphyllum elongatum (Morris) Retallack, 1981.

\section{Heidiphyllum elongatum (Morris) Retallack, 1981} (Figura 4A)

\section{Material estudiado. PBSJ 444.}

Estrato fosilífero y localidad. EF5, Miembro Inferior Gris, Formación Cortaderita, Triásico Medio, Localidad Quebrada de La Cortaderita.

Descripción. Fragmento de 2,9 cm de largo y 0,4 cm de ancho de una hoja linear-lanceolada, con base y ápice no preservados. Los márgenes y la venación son paralelos. La densidad de venas alcanza las 5 venas/cm (15 en total en la lámina).

Comentarios. Retallack (1981) creó el género Heidiphyllum para aquellas formas antiguamente incluidas dentro del género Podozamites Braun, 1843, pero que se diferenciaban de este último por su distribución exclusivamente gondwánica y la ausencia de un verdadero pecíolo. De esta manera, y en ausencia de cutícula, Heidiphyllum incluye hojas alargadas, lineares-elípticas a lineares-oblanceoladas, de base foliar apeciolada, que se angostan gradualmente; ápice foliar subagudo a redondeado obtuso; venas paralelas, bien espaciadas, a menudo con conspicuas estrías intervenas; que convergen cerca del ápice; cada una de las 2-4 venas basales se dicotomizan una o dos veces solamente cerca del ápice (Retallack, 1981). Los ejemplares aquí descriptos se pueden asimilar a la especie H. elongatum (Morris) Retallack, 1981.

\section{Heidiphyllum clarifolium \\ Anderson \& Anderson, 1989}

(Figuras 4B,C)

Materiales estudiados. PBSJ 445, 446.

Estrato fosilífero y localidad. EF5, Miembro Inferior Gris, Formación Cortaderita, Triásico Medio, localidad Quebrada de La Cortaderita.

Descripción. Hoja linear-oblanceolada, con una base muy angosta (pseudopeciolada). La lámina mide 2,5 a 4,2 cm de largo y 0,35 a 0,5 cm de ancho en la parte media de la lámina. El ápice es obtuso-redondeado. La venación se dicotomiza una vez en la base de la lámina, a partir de dos venas. Las cuatro venas que se originan son paralelas en la parte media de la lámina y tienden a convergir cerca del ápice.

Comentarios. La especie Heidiphyllum clarifolium fue erigida por Anderson \& Anderson (1989) para hojas pequeñas (de 7,5 cm de largo y 0,35 cm de ancho), linear-elípticas, con el ápice obtuso redondeado, base angosta sésil, venas bien espaciadas (10 por $\mathrm{cm})$, normalmente 4 venas por hoja que nacen de la bifurcación de dos venas en la base. Posteriormente, este taxón fue elevado a la categoría de género: Clariphyllum Anderson \& Anderson, 2003, como consecuencia de una reconsideración del género Heidiphyllum (Anderson \& Anderson, 2003). De acuerdo a estos autores, ambos géneros se distinguen porque Clariphyllum incluye hojas pequeñas, dispuestas en ramas con un arreglo helicoidal laxo, sin brácteas y con 4 venas paralelas por hoja; mientras que Heidiphyllum abarca hojas grandes, dispuestas en braquiblastos, con un arreglo en pseudoverticilos compactos con brácteas triangulares cortas y 10 venas paralelas por hoja. No obstante, estas diferencias no están contempladas en la diagnosis original de Heidiphyllum (Retallack, 1981) y H. clarifolium puede ser perfectamente asimilado al género. Los ejemplares aquí descriptos encajan con todos los atributos de la especie, siendo de menores dimensiones que el holotipo de la misma.

\section{Heidiphyllum minutifolium Anderson \& Anderson, 1989}

(Figura 4D)

1951 Podozamites lanceolatus var. minor (Schenk) Menéndez, p. 208-209, lám. 12, figs. 2-4. Formación Llantenes, Argentina, Triásico.

1967 Podozamites lanceolatus var. genuinus Heer, 1876, Jain \& Delevoryas, p. 581, lám. 97, figs. 6-8. Formación Cacheuta, Argentina, Triásico.

Material estudiado. PBSJ 447.

Estrato fosilífero y localidad. EF6, Miembro Inferior Gris, Formación Cortaderita, Triásico Medio, Localidad Quebrada de La Cortaderita. 
Descripción. Hoja oblanceolada, de 2,1 cm de largo y 0,67 $\mathrm{cm}$ de ancho máximo, con base angosta y ápice obtuso redondeado. Las venas se dicotomizan varias veces a diferentes alturas, a partir de 2 venas en la base, llegando a una densidad de 15 por centímetro cerca del ápice.

Comentarios. La especie Heidiphyllum minutifolium fue erigida por Anderson \& Anderson (1989) para hojas muy pequeñas (de $4 \mathrm{~cm}$ de largo y $0,5 \mathrm{~cm}$ de ancho), oblanceoladas, con el ápice redondeado, base angosta sésil, venas moderadamente espaciadas ( 15 por $\mathrm{cm})$, que se dicotomizan repetidamente a mitad de camino. A esta especie también puede asimilarse los ejemplares descriptos por Menéndez (1951) como Podozamites lanceolatus var. minor (Schenk) Menéndez, 1951 para la Formación Llantenes. Los especímenes de la Formación Llantenes se diferencian de $P$. lanceolatus porque esta última incluye hojas linearlanceoladas, con el ancho máximo más cerca de la base, de ápice agudo acuminado, y base contraída en un corto pecíolo; mientras que los ejemplares de Menéndez son formas oblanceoladas, con el ancho máximo más cerca del ápice, el que es redondeado, y con base angosta pero no contraída en un pecíolo. Estos atributos, más el tamaño de las hojas y las características de la venación, permiten asignar tanto al material de Menéndez, como al espécimen de la Formación Cortaderita aquí estudiado, a la especie H. minutifolium. Por otra parte, los especímenes descriptos por Jain \& Delevoryas (1967) como Podozamites lanceolatus var. genuinus Heer, 1876, también pueden incluirse en la especie H. minutifolium, dado que son hojas pequeñas y de ápice espatulado.

Afinidad sistemática de Heidiphyllum. Es un conspicuo componente de las floras triásicas gondwánicas. En Argentina presenta un amplio registro que va desde el Triásico Medio al Jurásico Inferior, hallándose en Mendoza, Santa Cruz, Río Negro y San Juan (Triásico) y Neuquén (Jurásico) (Morel et al., 2011).

Las hojas de Heidiphyllum elongatum frecuentemente se encuentran asociadas con conos de Telemachus elongatus en múltiples localidades del Triásico de Sudáfrica (Anderson, 1978), Antártida (Yao et al., 1993; Axsmith et al., 1998) y Argentina (Arce \& Lutz, 2010; Morel et al., 2011). Esta extendida asociación es una evidencia a favor de que H. elongatum y T. elongatus podrían haber sido producidos por la misma planta, de afinidad con las Volziaceae (Retallack, 1981; Anderson, 1978). Las Voltziaceae constituyen una familia cosmopolita de coníferas transicionales (=Voltziales) pérmicas, triásicas y jurásicas. Probablemente, representen un taxón artificial, debido a que incluyen formas con características intermedias entre las Voltziales más basales ("Walchianas" sensu Rothwell et al., 2005) y las familias de coníferas con representantes vivientes (Stewart \& Rothwell, 1993).

Particularmente, los conos megasporangiados de Telemachus presentan complejos bráctea-escama con características que sugieren vinculaciones con las Taxodiaceae (= Cupressaceae basales). De hecho, Escapa et al. (2010) consideran que las estructuras reproductivas de esta planta (Telemachus) son coincidentes con las de Parasciadopitys, previamente vinculada a las Taxodiaceae, y sólo representan diferentes modos preservacionales.

Recientemente, se ha publicado una reconstrucción de la planta completa de una Voltziaceae del Triásico de Antártida, que vincula órganos con diferentes modos de preservación y que a su vez previamente habían sido relacionados a diversas familias (Escapa et al., 2010; Bomfleur et al., 2013). Esta entidad abarcaría hojas y troncos permineralizados de la especie Notophytum kraeuselii Meyer-Berthaud \& Taylor, 1991 (vinculada con las Podocarpaceae, Meyer-Berthaud \& Taylor, 1991; Decombeix et al., 2011), impresionescompresiones de hojas y conos asignados a las especies Heidiphyllum elongatum y Telemachus antarticus Escapa, Decombeix, Taylor \& Taylor, 2010, respectivamente (Voltziaceae), conos permineralizados correspondientes a Parasciadopitys aequata Yao, Taylor \& Taylor, 1997 (considerada previamente como una forma intermedia entre Voltziaceae y Taxodiaceae, Yao et al., 1997), compresiones de conos polínicos de Switzianthus Anderson \& Anderson, 2003 ("Pteridospermas" de acuerdo a Anderson \& Anderson, 2003), y granos de polen del género Alisporites (relacionado tanto a las Voltziales, por Grauvogel-Stamm (1978, como a las Corystospermales por De Jersey, 1962). Sin embargo, la vinculación de estos órganos presenta algunas dificultades, en particular porque no todos provienen de la misma unidad estratigráfica, y entre ellos existen diferencias significativas a nivel anatómico, como es el caso de $N$. kraeuselii y $P$. aequata. Los conos permineralizados de esta última especie, carecen de canales resiníferos y las traqueidas del xilema secundario muestran punteaduras escalariformes, mientras que la primera especie presenta canales resiníferos en la corteza y hojas, y traqueidas del xilema secundario con punteaduras areoladas circulares.

\section{Orden PINALES (= CONIFERALES) \\ Gorozhankin, 1904 \\ Familia indeterminada}

Elatocladus Halle 1913 emend. Harris, 1979

Especie tipo. Elatocladus heterophylla Halle, 1913.

Elatocladus planus (Feistmantel) Seward, 1919

(Figuras 4E-H)

Materiales estudiados. PBSJ 448, 449, 451, 452.

Estrato fosilífero y localidad. EF5 y EF6, Miembro Inferior Gris, Formación Cortaderita, Triásico Medio, localidades Quebrada de La Cortaderita y Quebrada de la Tinta.

Descripción. Fragmentos de ramas de 0,03 a $0,32 \mathrm{~cm}$ de ancho y de 1,12 a $4,35 \mathrm{~cm}$ de largo, recorrida por finas estrías longitudinales, que lleva hojas sésiles distribuidas helicoidalemente. Las hojas son uninervias, de lámina linear a acicular, de ápice agudo; y miden 0,51 a 1,28 cm de largo y 0,03 a $0,84 \mathrm{~cm}$ de ancho. La vena media es conspicua.

Comentarios. El género Elatocladus fue creado por Halle (1913) para las ramas estériles de coníferas, tanto de simetría 
radial como dorsiventral, que no podían ser asignadas a géneros mejor definidos. Harris (1979) realizó sucesivas enmiendas de la diagnosis original, redefiniendo el género como: ramas que portan helicoidalmente hojas aplanadas dorsiventralmente, con una única vena, divergentes del eje. Posteriormente, otros autores (Townrow, 1967; Archangelsky, 1970; Anderson \& Anderson, 2003), incluyen en este género formas con hojas de disposición espiralada o en un solo plano, de simetría radial o bilateral, adpresas o no, cortas y falcadas a aplanadas y alargadas.

Para la Argentina y Antártida, se conocen las siguientes especies de este género: Elatocladus planus (Feistmantel) Seward, 1919 (Triásico-Jurásico), E. confertus (Oldham \& Morris) Halle, 1913 (Jurásico), E. australis Frenguelli, 1944 (Triásico-Cretácico), E. casamiquelensis Herbst \& Anzotegui, 1968 (Jurásico), E. heterophyllus Halle, 1913 (Jurásico), E. jabalpurensis (Feistmantel) Halle, 1913 (Jurásico), E. longifolius Baldoni, 1980a (Jurásico), E. palissyafolia? Berry, 1924 (Jurásico), y E. papillosus Baldoni, 1980b (Jurásico).

Los ejemplares aquí descriptos son determinados como Elatocladus planus (Feistmantel) Seward, 1919 porque comparte con esta especie las siguientes características: hojas uninervias alargadas, angostas, lineares, achatadas dispuestas helicoidalmente, base no contraída, y ápice simétrico.

Cabe destacar que este género ya había sido mencionado para la Formación Cortaderita por Bonetti (1963), como Elatocladus sp. Lamentablemente, el material original no ha sido encontrado, aunque la descripción y las fotografías aportadas por Bonetti (1963) permitirían asignarlo a la especie Elatocladus planus.

Afinidad sistemática de Elatocladus. Autores como White (1981) y Del Fueyo et al. (1990) sostienen que el material vegetativo de ciertas especies del género Rissikia se corresponde con los caracteres dados para Elatocladus australis y E. planus. De hecho, parte de los materiales aquí estudiados (PBSJ 448) fueron previamente asignados a la especie Rissikia media (Bodnar, 2010).

Elatocladus es un componente ecuménico de las floras desde el Triásico Medio hasta el Cretácico Temprano en Australia (Hill et al., 1966; McLoughlin \& Drinnan, 1995; Walkom, 1919), Antártida (Halle, 1913; Gee, 1989a,b), Sudamérica (e.g. Baldoni, 1980a,b,c), e India (e.g. Bose \& Banerji, 1984). Florin (1940) consideraba que la mayoría de los ejemplares asignados al morfogénero Elatocladus podían ser adscriptos a las Podocarpaceae. En efecto, las hojas de tipo Elatocladus del Hemisferio Sur son a menudo encontradas en conexión con conos podocarpáceos (e.g. Archangelsky, 1966; Archangelsky \& Del Fueyo, 2010).

Para aquellas hojas sin cutícula preservada o no asociada a estructuras reproductivas, las interpretaciones acerca de la afinidad con alguna familia son abiertas a duda, y la asignación de Elatocladus a otras familias (e.g. Cupressaceae s.l.) no puede ser descartada (Taylor et al., 2009). Registros jurásicos del Hemisferio Norte del género Elatocladus han sido relacionados a las Cupressaceae s.l. (Florin, 1922, 1958; Harris, 1943, 1979; Endo, 1951; Bose, 1961; Jongmans
\& Dijkstra, 1972). Sewardiodendron, un género jurásico asignado a las Cupressaceae s.l., tiene ramas foliosas que en estado estéril son determinadas como Elatocladus (Harris, 1979). Austrohamia, otro género Jurásico asignado a las Cupressaceae s.l. se caracteriza por tener ramas con hojas semejantes a las de Elatocladus (Escapa et al., 2008; Zhang et al., 2012).

\section{Ramas foliosas indeterminadas (Figuras 4I,J)}

\section{Material estudiado. PBSJ 450.}

Estrato fosilífero y localidad. EF5, Miembro Inferior Gris, Formación Cortaderita, Triásico Medio, Localidad Quebrada de la Tinta.

Descripción. Fragmentos de 5 y $6,5 \mathrm{~cm}$ de longitud de dos ramas, de 1 y $0,35 \mathrm{~cm}$ de grosor, respectivamente, recorridas por finas estrías longitudinales. Portan ramas de mayor orden de disposición alterna, de 0,4 a 0,5 cm de espesor. Hojas uninervias, escuamiformes; miden 0,33 a $0,4 \mathrm{~cm}$ de largo y 0,17 a $0,2 \mathrm{~cm}$ de ancho. La vena media es conspicua.

Comentarios. El material previamente fue designado al género Pagiophyllum Heer emend. Harris, 1979 (Bodnar, 2010). Sin embargo, como sólo se preservó la parte basal de las ramas de último orden, no se puede afirmar que toda la rama haya tenido hojas escuamiformes. Entre las coníferas, es muy común el polimorfismo foliar (Govil, 2007). Por ejemplo, en el género Sequoia (Figura 7) las hojas son de dos tipos: en las ramas principales y las que portan los conos, las hojas son escuamiformes y tienen una disposición helicoidal, mientras que en las ramas laterales, son lineares y aplanadas, con un arreglo dístico (Tutin, 1993). Las ramas laterales generalmente portan en la base, hojas escuamiformes (Fralish \& Franklin, 2002). Considerando este caso, y ya que estas ramas se encuentran en íntima asociación con hojas de la especie Elatocladus planus, es posible que las primeras representen las ramas principales (o de anteúltimo orden) de la misma planta cuyas ramas laterales (o de último orden) están representadas por dicha especie.

\section{Familia CUPRESSACEAE sensu lato (sensu Eckenwalder, 1976)}

$$
\text { Cupressinoxylon Göppert, } 1850
$$

Especie tipo. Cupressinoxylon gothanii Kräusel, 1920.

Cupressinoxylon zamunerae sp. nov. (Figura 5)

Holotipo. PBSJ 828/ PBSJPm 828.

Paratipos. PBSJ 827/ PBSJPm 827; PBSJ 829/ PBSJPm 829; PBSJ 830/ PBSJPm 830; PBSJ 831/ PBSJPm 831.

Nivel estratigráfico y edad. EF5 y EF6, Miembro Inferior Gris, Formación Cortaderita, Triásico Medio.

Localidad tipo. Quebrada de la Tinta, área de Barreal, Cuenca de Barreal Calingasta, provincia de San Juan, Argentina. 

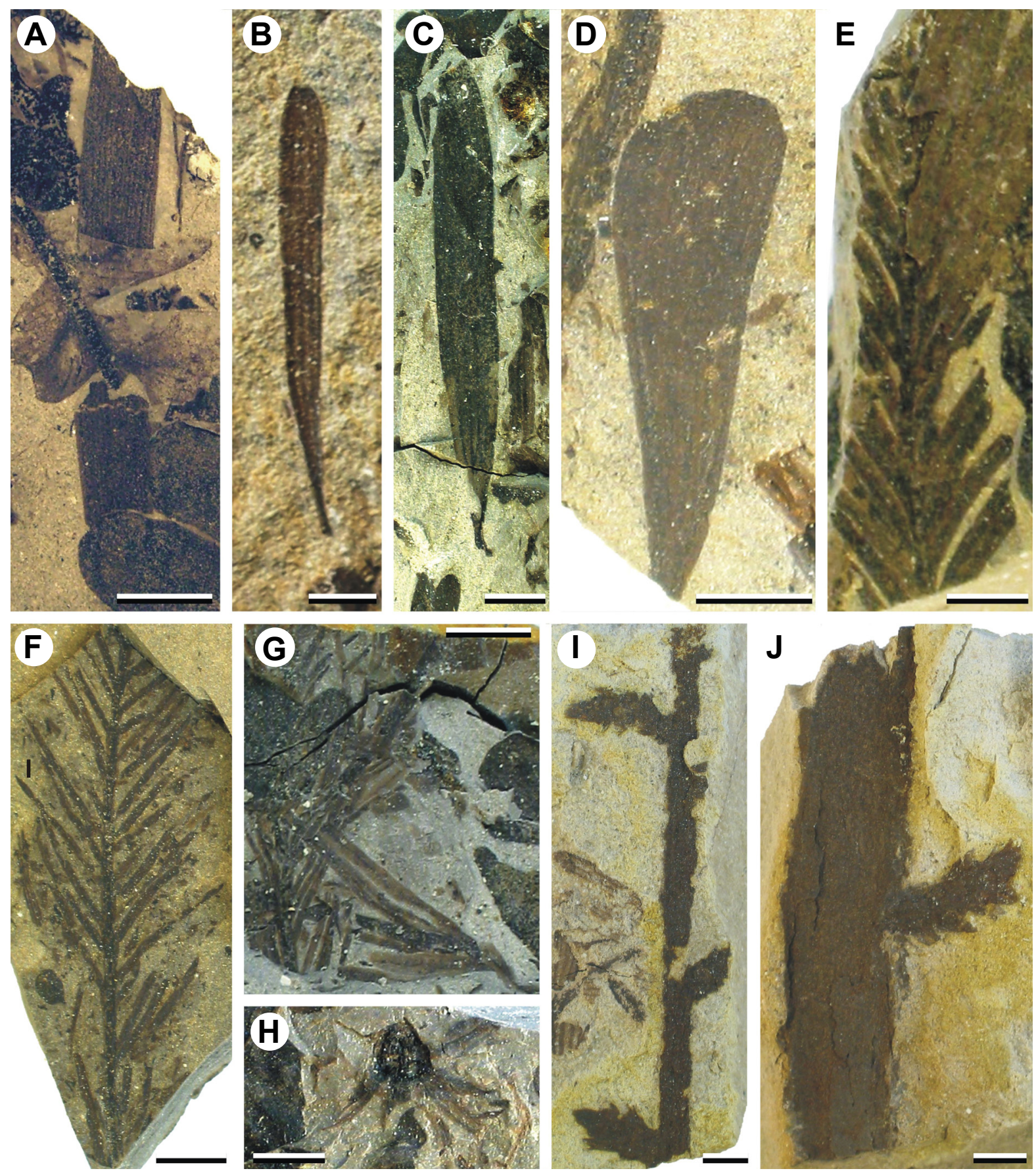

Figura/Figure 4. A, Heidiphyllum elongatum (Morris) Retallack, 1981. PBSJ 444. B, C, Heidiphyllum clarifolium Anderson \& Anderson, 1989 B, PBSJ 445. C, PBSJ 446. D, Heidiphyllum minutifolium Anderson \& Anderson, 1989. PBSJ 447. E, F, G, H, Elatocladus plana (Feistmantel) Seward, 1919. E, PBSJ 449. F, PBSJ 448. G, PBSJ 451. H, PBSJ 452. I, J, Ramas foliosas de coníferas indeterminadas/ Indeterminate conifer leafy twigs. PBSJ 450. Escalas/ Scale bars: A-D, F, H-J = $5 \mathrm{~mm} ; \mathrm{E}, \mathrm{G}=3 \mathrm{~mm}$.

Etimología. El nombre específico está dedicado a la memoria de la Dra. Alba Berta Zamuner, por sus fundamentales aportes y extensivos estudios sobre la anatomía de leños fósiles de la Argentina.

Diagnosis. Leño secundario homoxílico picnoxílico con anillos de crecimiento definidos y variables en su ancho (19 a 57 células). Transición abrupta entre leño temprano y tardío, capa de leño tardío con 1 a 3 células de espesor. Punteaduras en las paredes radiales de las traqueidas areoladas, circulares y espaciadas, predominantemente uniseriadas, con poro circular y torus conspicuo. Parénquima axial escaso y difuso. Campos de cruzamiento con 1-2 oculiporos de tipo cupresoide, en una hilera. Radios heterocelulares, mayormente uniseriados y de 4-33 células de altura. Células de los radios con paredes horizontales punteadas, paredes terminales engrosadas y levemente dentadas.

Diagnosis. Pycnoxylic homoxylic secondary wood with distinct growth rings of variable width (19 to 57 cells). Abrupt 
transition from earlywood to latewood; latewood 1 to 3 cells wide. Tracheid pits in radial walls bordered, circular and spaced, predominantly uniseriate, with circular pore and conspicuous torus. Axial parenchyma scarce and diffuse. Cross-fields with 1-2 oculipores of cupressoid type, in one row. Heterocellular, mainly uniseriate, and 4-33 cells high rays. Ray cells with pitted horizontal walls, and thickened and indented end walls.

Descripción. Se describen tres fragmentos, pertenecientes a troncos fósiles permineralizados, de $7 \mathrm{~cm}$ hasta $24 \mathrm{~cm}$ de diámetro, con médula y xilema secundario preservados. Los ejemplares de menor porte pertenecen a ramas, con médula excéntrica y leño de compresión. En estos últimos la médula está deformada, mide $0,6 \mathrm{~cm}$ de diámetro, y aunque sus detalles celulares no se distinguen se puede observar evidencias de actividad de insectos xilófagos (galerías y pellets fecales) (Figura 6)

En todas las muestras, el leño es homoxílico y picnoxílico. En corte transversal se observan anillos de crecimiento definidos, con una amplitud variable, comprendida entre 19 a 57 células de ancho, con una transición abrupta entre el leño temprano y el leño tardío, siendo la capa de leño tardío de 1 a 3 células de espesor (Figuras 5A-B).

Las traqueidas tienen una sección transversal cuadrangular, y están tangencialmente comprimidas (Figuras 5B). El diámetro radial de las traqueidas del leño temprano tiene en promedio $46,85 \mu \mathrm{m}(35-60 \mu \mathrm{m})$; mientras que su diámetro medio tangencial es de 29,35 $\mu \mathrm{m}(20-45 \mu \mathrm{m})$. El espesor de la doble pared varía de 5 a $12,5 \mu \mathrm{m}$, con un promedio de 8,92 $\mu \mathrm{m}$. En el leño tardío las traqueidas presentan un diámetro radial promedio de $20 \mu \mathrm{m}(10-50 \mu \mathrm{m})$ y un diámetro medio tangencial de $24 \mu \mathrm{m}(15-30 \mu \mathrm{m})$. El espesor de la doble pared va de 7,5 a $15 \mu \mathrm{m}$, con un promedio de $11,25 \mu \mathrm{m}$.

En el corte longitudinal radial, las traqueidas tienen extremos ahusados y presentan punteaduras areoladas y de forma circular en sus caras radiales, disponiéndose en un plan abietinoide (uniseriadas y espaciadas) (Figuras 5C-D), con un diámetro promedio de $14,45 \mu \mathrm{m}(10-22,5 \mu \mathrm{m})$. La apertura de las punteaduras es circular y su diámetro medio es 4,43 $\mu \mathrm{m}(2,5-7,5 \mu \mathrm{m}) \mathrm{y}$ en el interior se observa la presencia de un torus de límites algo irregulares, cuyo diámetro medio es de 5,21 $\mu \mathrm{m}(2,5-10 \mu \mathrm{m})$. También está preservado el margo alrededor del torus (Figuras 5E-G).

Los radios son heterocelulares, con traqueidas radiales dispersas (Figura 5E). Las células parenquimáticas son rectangulares, orientadas horizontalmente, con paredes horizontales punteadas, y paredes terminales engrosadas y levemente dentadas a algo oblicuas (Figuras 5H-L). Las células parenquimáticas de los radios miden de 7,5 a 22,5 $\mu \mathrm{m}$ de altura, con un promedio de $15,57 \mu \mathrm{m}$; y 10 a $25 \mu \mathrm{m}$ de ancho, con un promedio de 14,67 $\mu \mathrm{m}$. Los campos de cruzamiento son del tipo cupresoide (sensu IAWA, 2004) (Figuras 5H-J). El 70\% de los campos posee dos punteaduras dispuestas en una hilera, y el restante $30 \%$, una única punteadura. En todos los casos las punteaduras son del tipo cupresoide (= areoladas y con la apertura elíptica) con un diámetro medio de 3,45 $\mu \mathrm{m}(2,5-5 \mu \mathrm{m})$.
En corte longitudinal tangencial se observa con dificultad las paredes de las traqueidas debido a que se encuentran deterioradas. El parénquima axial es escaso y difuso (Figura $5 \mathrm{~N})$. Las células del parénquima axial son rectangulares, de $127,5 \mu \mathrm{m}(77,5-192,5 \mu \mathrm{m})$ de altura y $27,08 \mu \mathrm{m}(20-37,5 \mu \mathrm{m})$ de diámetro radial. Las paredes horizontales de las células tienen engrosamientos irregulares, del tipo nodular. Los radios son predominantemente uniseriados, la altura oscila entre 4 y 33 células, con un promedio de 14 células (Figuras 5M-O).

Se pudieron observar dos trazas rameales, de contorno romboidal, de 500 y $700 \mu \mathrm{m}$ de altura, y $200 \mu \mathrm{m}$ de ancho máximo, conformadas mayormente por células parenquimáticas de orientación radial.

Comentarios. El género Cupressinoxylon Göppert, 1850 (nomen conservandum vide Bamford et al., 2002) originalmente fue propuesto con una diagnosis que incluía caracteres de la corteza y la médula. De acuerdo a Phillippe \& Bamford (2008) también puede ser usado para leños homoxilados aislados en base a su descripción original. En la descripción original y en publicaciones posteriores, Cupressinoxylon es usado tanto para leños con una anatomía similar al género actual Cupressus, como para aquellos semejantes a las Cupressaceae vivientes en general (Vaudois \& Privé, 1971).

Este morfogénero se define como leños con radios uniseriados, punteaduras areoladas, punteado abietinoide en las paredes radiales de las traqueidas, campos de cruzamientos con punteaduras de tipo oculiporos cupresoides, parénquima axial presente o ausente y células radiales con paredes horizontales lisas o con pequeñas punteaduras y paredes terminales lisas (Phillippe \& Bamford, 2008). Al ser esta caracterización poco delimitada, dentro de este género pueden adscribirse diversas formas. A su vez, la utilización de este género en la literatura paleobotánica no se limita a la definición dada por Phillippe \& Bamford (2008) sino que comprende también leños con punteaduras de las traqueidas mixtas (Vaudois \& Privé, 1971). Cupressinoxylon zamunerae se ajusta a la anterior descripción del género.

El género Cupressinoxylon ha sido descripto para ambos hemisferios, en rocas cuya edad varía desde el Triásico Tardío hasta el Mioceno (e.g. Lutz, 1930; Lemoigne, 1967; Ru-feng et al., 1996; Morgans et al., 1999; Falcon-Lang \& Cantrill, 2001; Falcon-Lang, 2003; Philippe et al., 2004).

En Gondwana, son escasas las especies atribuidas a Cupressinoxylon. Particularmente en Sudamérica, para el Jurásico Jaworski (1915) mencionó un fragmento de madera encontrado en la Argentina, y determinada por Gothan como "Cupressinoxylon sp.". Este ejemplar proviene de ChacayMelehue, Provincia del Neuquén y su edad es probablemente toarciano-bajociana (H. Parent, pers. comm., 2000 in Torres \& Philippe, 2002). De la misma localidad, Eckhold (1923) describió a Cupressinoxylon krauselii. Sin embargo, la atribución genérica de esta madera ha sido puesta en duda por la mayoría de los autores que la han citado, debido a su mala preservación y a su diagnosis imprecisa (Kräusel, 1949; Vaudois \& Privé, 1971) y probablemente sea más cercana al género Agathoxylon (Egerton, 2011). 

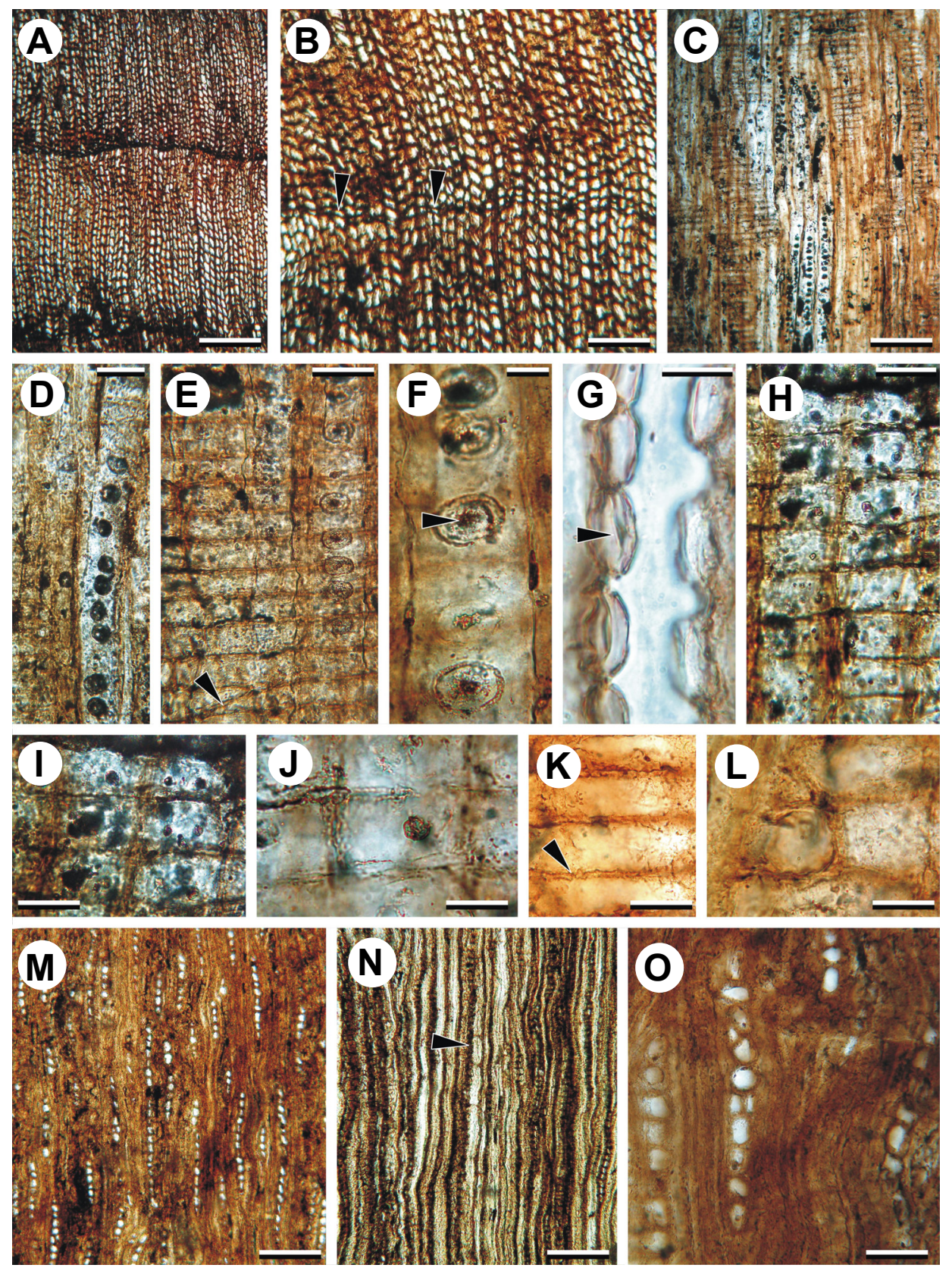

Figura 5. Cupressinoxylon zamunerae sp. nov. Vista bajo el microscopio óptico. A, PBSJPm 828, corte transversal que muestra los anillos de crecimiento. B, PBSJPm 828, límite de un anillo de crecimiento en corte transversal, las flechas señalan las células del leño tardío. C, PBSJPm 828 , vista general del corte radial. D, PBSJPm 828, detalle de las punteaduras radiales de una traqueida. E, PBSJPm 828, detalle del corte radial, donde se muestra el punteado abietinoide de una traqueida y la morfología de las células radiales. La flecha señala una traqueida radial. F, PBSJPm 828, detalle de las punteaduras areoladas y el torus (flecha). G, PBSJPm 828, corte tangencial, que muestra las punteaduras radiales de las traqueidas y su torus en vista lateral (flecha). H, PBSJPm 828, campos de cruzamiento de tipo cupresoide. I, PBSJPm 828 , detalle de los campos de cruzamiento. J, PBSJPm 828, detalle de un campo de cruzamiento con una única punteadura. K, PBSJPm 829, paredes horizontales de las células de los radios engrosadas y punteadas (flecha). L, PBSJPm 829, detalle de las paredes terminales de las células de los radios. M, PBSJPm 829, vista general del corte tangencial, mostrando radios mayormente uniseriados. N, PBSJPm 828, parénquima axial (flecha) en corte tangencial. O, PBSJPm 829, detalle de un radio parcialmente biseriado. Escalas: $A=300 \mu \mathrm{m} ; \mathrm{B}=200 \mu \mathrm{m} ; \mathrm{C}=160 \mu \mathrm{m}$; $\mathrm{D}-\mathrm{E}=40 \mu \mathrm{m} ; \mathrm{F}-\mathrm{G}=10 \mu \mathrm{m} ; \mathrm{H}=30 \mu \mathrm{m} ; \mathrm{I}=25 \mu \mathrm{m} ; \mathrm{J}-\mathrm{L}=15 \mu \mathrm{m} ; \mathrm{K}=20 \mu \mathrm{m} ; \mathrm{M}-\mathrm{N}=100 \mu \mathrm{m} ; \mathrm{O}=50 \mu \mathrm{m}$.

Figure 5. Cupressinoxylon zamunerae sp. nov. View under optical microscope. A, PBSJPm 828 , cross section showing the growth rings. B, PBSJPm 828, cross section of growth boundary, arrows point at latewood cells. C, PBSJPm 828, general view of radial section. D, PBSJPm 828, detail of tracheid radial pits. E, PBSJPm 828, detail of radial section, showing the abietinoid tracheid pitting and morphology of ray cells. Arrow points one ray tracheid. F, PBSJPm 828, detail of radial bordered pits and torus (arrow). G, PBSJPm 828, tangential section, showing tracheid radial pits and their torus in lateral view (arrrow). H, PBSJPm 828, cupressoid cross fields. I, PBSJPm 828, detail of cross fields. J, PBSJPm 828, detail of a cross fields with one pit. K, PBSJPm 829, ray cell horizontal walls with thickenings and pits (arrow). L, PBSJPm 829 , detail of ray cell end walls. M, PBSJPm 829 , general view of tangential section, showing mainly uniseriate rays. N, PBSJPm 828 , axial parenchyma (arrow) in tangential section. $\mathrm{O}, \mathrm{PBSJPm} 829$, detail of a partially biseriate ray. Scale bars: $A=300 \mu \mathrm{m} ; \mathrm{B}=200 \mu \mathrm{m} ; \mathrm{C}=160 \mu \mathrm{m}$; $\mathrm{D}-\mathrm{E}=40 \mu \mathrm{m} ; \mathrm{F}-\mathrm{G}=10 \mu \mathrm{m} ; \mathrm{H}=30 \mu \mathrm{m} ; \mathrm{I}=25 \mu \mathrm{m} ; \mathrm{J}-\mathrm{L}=15 \mu \mathrm{m} ; \mathrm{K}=20 \mu \mathrm{m} ; \mathrm{M}-\mathrm{N}=100 \mu \mathrm{m} ; \mathrm{O}=50 \mu \mathrm{m}$. 

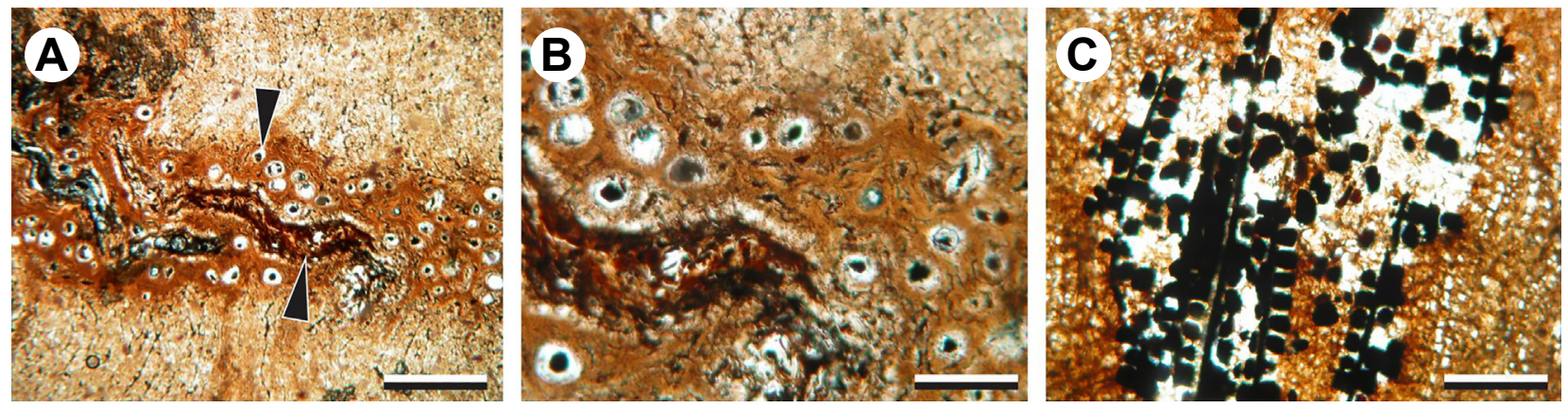

Figura 6. Cupressinoxylon zamunerae sp. nov. A, médula en corte transversal, con una galería y cavidades con pellets fecales (flecha), probablemente de artrópodos. B, detalle de las cavidades con pellets fecales. $\mathbf{C}$, corte transversal del xilema secundario, con pellets fecales que reproducen el contorno de las células preexistentes. Escalas: $A=1 \mathrm{~mm} ; B=0,5 \mathrm{~mm} ; C=0,5 \mathrm{~mm}$.

Figure 6. Cupressinoxylon zamunerae sp. nov. A, cross section of the pith, showing a gallery and cavities with fecal pellets. B, detail of the cavities with fecal pellets. C, cross section of secondary xylem, showing fecal pellets that take the form of pre-existing cells. Scale bars: $A=1 \mathrm{~mm}$; $B=0,5 \mathrm{~mm} ; C=0,5 \mathrm{~mm}$

Oliveira (1936) describió a la especie Cupressinoxylon camponovensis para el Cretácico Temprano de la región de Mato Grosso, Brasil. Esta especie también fue mencionada por Dolianiti (1948) para la misma localidad. No obstante, fue atribuida posteriormente al género Agathoxylon (Menéndez, 1969; Philippe et al., 2004). Kräusel (1949) describió la especie Cupressinoxylon hallei, sobre la base de restos hallados en la Patagonia argentina, aunque su edad puede ser tanto cretácica como "terciaria". Posteriormente Vaudois \& Privé (1971) sugirieron que pertenecía al género Widdringtonioxylon. Recientemente, Martínez (2010) describió varias especies nuevas de Cupressinoxylon para el Cretácico Superior de Neuquén, Argentina, pero probablemente pertenezcan a otros géneros de filiación cupresácea (Martínez, pers. comm.). En su tesis inédita, Egerton (2011) describió leños asignables al género Cupressinoxylon, en el Cretácico Superior de la Provincia de Santa Cruz, Argentina.

Para el Terciario, las descripciones y citas son más precisas y abundantes. Conwentz (1885) describió a Cupressinoxylon sp., C. latiporosum y C. patagonicum en el Oligoceno de la Provincia de Río Negro (Herbst et al., 2007). De acuerdo a Kräusel (1924), C. latiporosum es asignable al género Phyllocladoxylon, por el tipo de campo de cruzamiento. De todos modos, la ausencia de ilustraciones y fotografías, y la incompleta descripción en el trabajo original de Conwentz (1885), impide la comparación de estas especies en detalle. Para Chile, fueron descriptas las especies Cupressinoxylon austrocedroides Nishida, 1984a (Mioceno) y Cupressinoxylon magellanicum Nishida \& Nishida, 1988 (Eoceno-Oligoceno) en la Patagonia, y C. mochaense Nishida, 1984b (Mioceno) en la Isla Mocha (Nishida, 1984a,b; Nishida \& Nishida, 1988).

En el resto del Gondwana, también muchas especies de Cupressinoxylon han sido reconsideradas como otros géneros (ver Philipe et al., 2004). Para el Mesozoico, las descripciones reconocidas incluyen a Cupressinoxylon rajmahalense Bhardwaj, 1953 del Jurásico de la India, y C. kotaense Rajanikanth \& Sukh-Dev, 1989 y C. gondwanensis Kumarasamy \& Jeyasingh, 2004 del Cretácico temprano del mismo país. Para el Eoceno de Antártida se citaron a
Cupressinoxylon sp. (Poole et al., 2001), Cupressinoxylon sp. A (Pujana, 2008) y Cupressinoxylon seymourense Torres, Marenssi \& Santillana (Torres et al., 1994),

En la comparación, se utilizaron las especies aceptadas para Gondwana y algunas especies que si bien está en duda su asignación al género, presentaban semejanzas con los materiales descriptos.

De estos taxones gondwánicos, la nueva especie claramente se diferencia por las paredes horizontales de las células radiales punteadas (Tabla 1). Por poseer radios muy altos Cupressinoxylon zamunerae sp. nov. se acerca más a $C$. patagonicum, pero se distingue de esta última porque tiene hasta dos punteaduras por campo de cruzamiento (C. patagonicum puede tener hasta 4).

Afinidad sistemática de Cupressinoxylon zamunerae. $\mathrm{Si}$ bien existen caracteres convergentes, en los leños del Orden Pinales, la combinación de ciertos rasgos puede dar una idea de la afinidad sistemática a nivel de familia. En este caso, Cupressinoxylon zamunerae sp. nov. tiene características que la acerca a la Familia Cupressaceae s.l. El clado de las Cupressaceae s.l. es el más diverso y ampliamente distribuido dentro de las coníferas, con 30 géneros vivientes (Taylor et al., 2009). Dentro del mismo, se incluyen tanto a las antiguas Taxodiaceae (consideradas como el grado basal del linaje) y a las Cupressaceae s.s (consideradas el clado más derivado del grupo) (Eckenwalder, 1976; Gadek et al., 2000; Farjon \& Ortiz García, 2003; Farjon, 2005). Los leños de ambos grupos presentan diversas semejanzas; i.e. presencia de anillos de crecimiento, ausencia de canales resiníferos, parénquima axial frecuente, a veces con paredes nodulares, punteaduras de las traqueidas uni a multiseriadas, generalmente de tipo abietinoide, campos de cruzamiento con 1-6 oculiporos, radios uniseriados, células parenquimáticas de los radios a veces dentadas y con engrosamientos nodulares (Peirce, 1937; Kräusel, 1949; Boutelje, 1955; Greguss, 1955; Boureau, 1956; Bonetti, 1966; Patel, 1968; Vaudois \& Privé, 1971; Roig, 1992; De Magistris, 1997; Gadek et al., 2000). Algunos de los rasgos que permiten diferenciar un leño de Taxodiaceae con uno de Cupressaceae s.s. son los campos de cruzamiento, 
Tabla 1. Cuadro comparativo de las especies de Cupressinoxylon del Gondwana. Abreviaturas: PRT, punteaduras radiales de las traqueidas; PTT, punteaduras tangenciales de las traqueidas; PA, parénquima axial; PHPA, paredes horizontales del parénquima axial; CC, punteaduras de los campos de cruzamiento; PPR, paredes del parénquima radial; TR, traqueidas radiales; $\mathbf{R}$, radios.

Table 1. Comparative table of Gondwanan Cupressinoxylon species. Abbreviations: PRT, radial tracheid pits; PTT, tangentiales tracheid pits; PA, axial parenchyma; PHPA, horizontal walls of axial parenchyma; CC, cross-field pits; PPR, walls of ray parenchyma; TR, ray tracheids; $\mathbf{R}$, rays.

\begin{tabular}{|c|c|c|c|c|c|c|}
\hline & Edad & Localidad & Anillos & PRT (series) & PRT (arreglo) & PTT \\
\hline C. zamunerae sp. nov. & Triásico Medio & $\begin{array}{l}\text { San Juan, } \\
\text { Argentina }\end{array}$ & definidos & $\begin{array}{l}\text { mayormente } \\
\text { uniseriadas }\end{array}$ & espaciadas & ausentes \\
\hline C. kotaense & Jurásico Medio & Maharashtra, India & $\begin{array}{l}\text { débilmente } \\
\text { definidos }\end{array}$ & $\begin{array}{l}\text { uniseriadas, biseriadas } \\
\text { ocasionales }\end{array}$ & $\begin{array}{l}\text { contiguas y } \\
\text { espaciadas }\end{array}$ & $?$ \\
\hline C. rajmahalense & $\begin{array}{c}\text { Jurásico Tardío- } \\
\text { Cretácico Temprano }\end{array}$ & $\begin{array}{l}\text { Rajmahal hills, } \\
\text { Jharkhand, India }\end{array}$ & definidos & uni-biseriadas & $\begin{array}{l}\text { opuestas, contiguas, } \\
\text { con barras de sanio }\end{array}$ & ausente \\
\hline C. gondwanensis & Cretácico temprano & Tamil Nadu, India & definidos & uni-biseriadas & $\begin{array}{l}\text { mayormente } \\
\text { espaciadas }\end{array}$ & ausente \\
\hline Cupressinoxylon sp. & Cretácico Superior & $\begin{array}{l}\text { Santa Cruz, } \\
\text { Argentina }\end{array}$ & definidos & uniseriadas & espaciadas & ocasionales \\
\hline C. seymourense & Eoceno & $\begin{array}{l}\text { Isla Marambio, } \\
\text { Antártida }\end{array}$ & muy definidos & uniseriadas, & espaciadas & ausentes \\
\hline Cupressinoxylon sp. & Eoceno & $\begin{array}{l}\text { Islas Shetland del } \\
\text { Sur, Antártida }\end{array}$ & definidos & $\begin{array}{c}\text { uniseriadas, biseriadas } \\
\text { ocasionales }\end{array}$ & espaciadas & ocasionales \\
\hline Cupressinoxylon sp. A & Eoceno & $\begin{array}{c}\text { Isla Marambio, } \\
\text { Antártida }\end{array}$ & bien definidos & uni-biseriadas & opuestas, espaciadas & ausentes \\
\hline C. magellanicum & Eoceno-Oligoceno & Patagonia chilena & $?$ & uniseriadas & espaciadas & ocasionales \\
\hline C. latiporosum & Oligoceno & $\begin{array}{l}\text { Río Negro, } \\
\text { Argentina }\end{array}$ & $?$ & uni-biseriadas & opuestas, espaciadas & presentes \\
\hline C. patagonicum & Oligoceno & $\begin{array}{l}\text { Río Negro, } \\
\text { Argentina }\end{array}$ & definidos & uniseriadas & espaciadas & ausentes \\
\hline C. austrocedroides & Mioceno & Patagonia chilena & definidos & uniseriadas & espaciadas & presentes \\
\hline C. mochaense & Mioceno & Isla Mocha, Chile & $\begin{array}{l}\text { débilmente } \\
\text { definidos }\end{array}$ & uniseriadas & espaciadas & presentes \\
\hline
\end{tabular}

\begin{tabular}{|c|c|c|c|c|c|c|c|}
\hline & $\mathrm{PA}$ & PHPA & $\mathrm{CC}$ & PPR & TR & $\mathrm{R}$ (ancho) & $\mathrm{R}$ (alto) \\
\hline C. zamunerae sp. nov. & escaso & lisas & cupresoides & lisas & presentes & $\begin{array}{l}\text { uniseriados, parcialmente } \\
\text { biseriados raros }\end{array}$ & 4-33 células \\
\hline C. kotaense & ausente & ---- & $\begin{array}{c}2-4 \\
\text { cupresoides }\end{array}$ & lisas & ausentes & uniseriados & 1-13 células \\
\hline C. rajmahalense & ausente & --- & $\begin{array}{c}1-2 \\
\text { cupresoides }\end{array}$ & lisas & ausentes & uni-biseriados & 1-23 células \\
\hline C. gondwanensis & ausente & ---- & $\begin{array}{c}1-2 \\
\text { cupresoides }\end{array}$ & $\begin{array}{c}\text { algo } \\
\text { engrosadas }\end{array}$ & ausentes & uniseriados & 1-11 células \\
\hline Cupressinoxylon sp. & difuso & $?$ & $\begin{array}{c}1-2 \\
\text { cupresoides }\end{array}$ & lisas & ausentes & uniseriados & 1-11 células \\
\hline C. seymourense & presente & $\begin{array}{l}\text { engrosadas o } \\
\text { lisas }\end{array}$ & $\begin{array}{c}1-4 \\
\text { taxodioides }\end{array}$ & lisas & ausentes & $\begin{array}{c}\text { uniseriados, biseriados } \\
\text { escasos }\end{array}$ & 1-13 células \\
\hline Cupressinoxylon sp. & escaso? & $?$ & $\begin{array}{c}1-2 \\
\text { cupresoides }\end{array}$ & lisas & ausentes & uniseriados & 1-14 células \\
\hline Cupressinoxylon sp. A & presente & $?$ & $\begin{array}{c}2-4 \\
\text { cupresoides }\end{array}$ & lisas & ausentes & uniseriados & $1-19$ células \\
\hline C. magellanicum & difuso & $?$ & 4 cupresoides & lisas & ausentes & uniseriados & 1-20 células \\
\hline C. latiporosum & abundante & $?$ & $\begin{array}{c}1-2 \\
\text { cupresoides }\end{array}$ & lisas & $?$ & uniseriados & 1-18 células \\
\hline C. patagonicum & presente & $?$ & $\begin{array}{c}2-4 \\
\text { cupresoides }\end{array}$ & lisas & $?$ & $\begin{array}{c}\text { uniseriados, biseriados } \\
\text { escasos }\end{array}$ & 1-29 células \\
\hline C. austrocedroides & escaso & lisas & $\begin{array}{c}1-2 \\
\text { cupresoides }\end{array}$ & lisas & ausentes & uniseriados & 1-10 células \\
\hline C. mochaense & ausente & ---- & $\begin{array}{c}3-6 \\
\text { cupresoides }\end{array}$ & lisas & ausentes & $\begin{array}{l}\text { uniseriados, algunos } \\
\text { biseriados }\end{array}$ & $1-20$ células \\
\hline
\end{tabular}


los que son casi siempre taxodioides en el primer grupo, y cupresoides a taxodioides en el segundo; y la presencia de engrosamientos callitroides que sólo ocurren en un género de Cupressaceae s.s. (Greguss, 1955).

Todas las características comunes entre Taxodiaceae y Cupressaceae s.s. también son apreciadas en Cupressinoxylon zamunerae lo que aporta evidencia a favor para su asignación a las Cupressaceae s.l.

\section{DISCUSIÓN}

\section{Reconstrucción de Cupressinoxylon zamunerae/Elatocla- dus planus}

En la Formación Cortaderita, las hojas de Elatocladus planus se han encontrado en los mismos estratos fosilíferos que los leños de Cupressinoxylon zamunerae sp. nov. Los restos fósiles de ambos taxones se han utilizado para reconstruir como habría sido la conífera que formaba parte de los bosques permineralizados de dicha unidad formacional (Figura 7). Elatocladus planus fue hallado en íntima
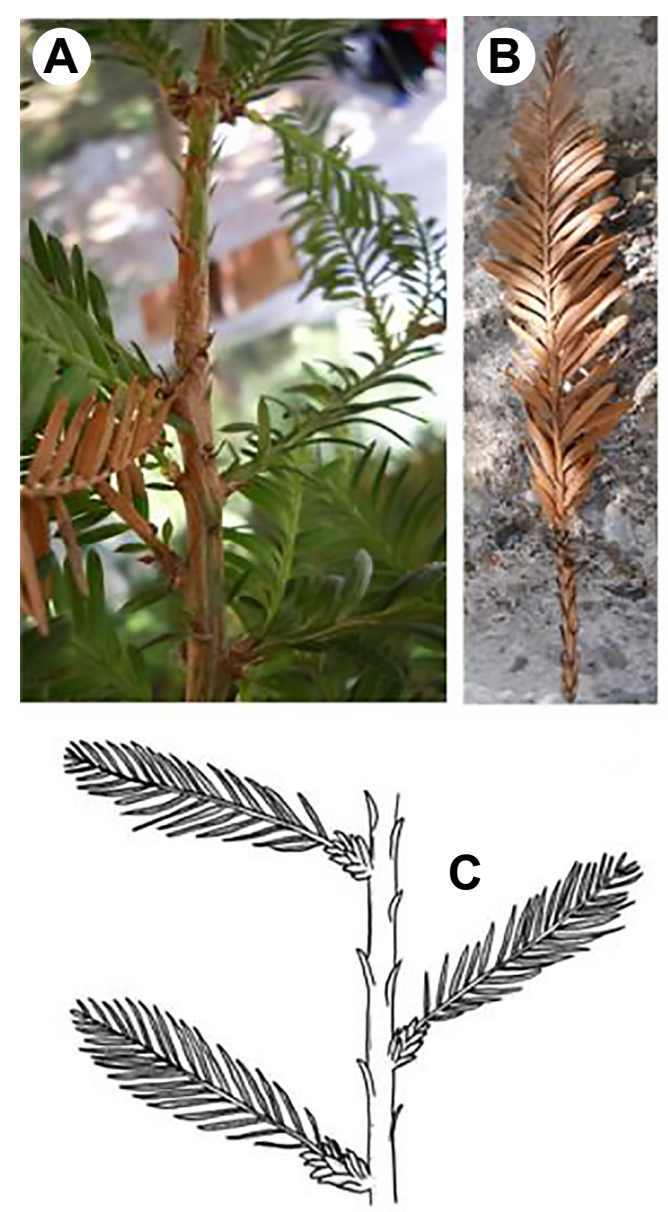

asociación con impresiones-compresiones de ramas. Estas ramas, que llevan hojas escuamiformes, portan de manera alterna ramas de mayor orden. Las ramas de mayor orden en su base también tienen hojas escuamiformes. La parte media y apical de las ramas de último orden, estarían representadas por los ejemplares asignados a E. planus. Este tipo de dimorfismo foliar es común en las especies actuales de Cupressaceae s.l., como Sequoia sempervirens y Taxodium distichum (Fralish \& Franklin, 2002).

Asimismo, los troncos de Cupressinoxylon zamunerae se han encontrado junto a ramas permineralizadas de $7 \mathrm{~cm}$ de diámetro, que presentan una médula excéntrica y leño de compresión. El diámetro de los troncos de C. zamunerae ha permitido realizar inferencias acerca de altura de los árboles en vida, a partir de las fórmulas de Niklas (1994a,b,c). Se pudo calcular que estos árboles llegaban en promedio a una altura de $13 \mathrm{~m}$.

Anderson \& Anderson (1985) propusieron una escala para determinar el grado de certeza en la vinculación de diferentes órganos fósiles para la reconstrucción de la planta entera.

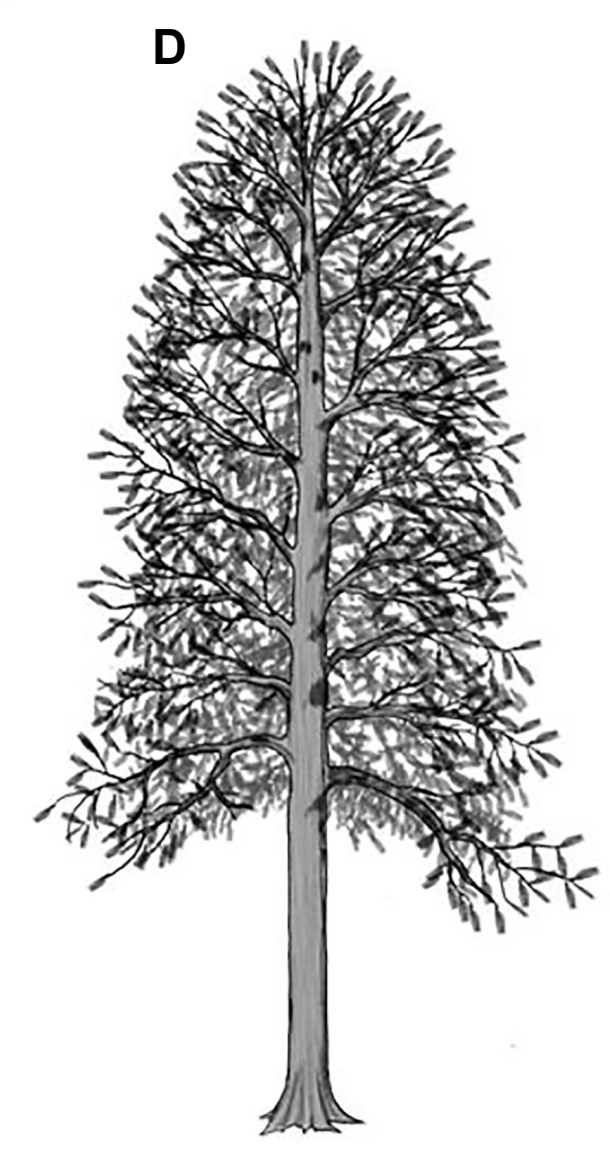

Figura 7. Reconstrucción de la planta entera. A, B, ramas de Sequoia sempervirens mostrando el dimorfismo foliar. Fotografía tomada en Peulla, Chile. C, reconstrucción de una rama completa de los especímenes de Elatocladus planus y ramas asociadas, provenientes de la Formación Cortaderita. D, reconstrucción del árbol con leño de la especie Cupressinoxylon zamunerae y ramas de E. planus.

Figure 7. Whole-plant reconstruction. A,B, branchs of Sequoia sempervirens, showing the leaf dimorphism. Photograph taken in Peulla, Chile. C, reconstruction of a entire branch of Elatocladus planus specimens and linked branchs, from the Cortaderita Formation. D, reconstruction of the entire tree with the wood of Cupressinoxylon zamunerae and the branches of E. planus. 
En esta escala se proponen que los criterios para relacionar dos o más órganos son los siguientes (del más confiable al menos confiable): la conexión orgánica, la similitud morfológica, soporte por afinidad y ocurrencia mutua. En el presente caso, los fósiles se encontraron asociados en los mismos estratos fosilíferos, por lo que cumplen el criterio de ocurrencia mutua. En cuanto al soporte por afinidad, si bien los taxones Elatocladus y Cupressinoxylon no han sido anteriormente empleados en conjunto en una reconstrucción, ambos han sido vinculados a las Cupressaceae s.l. De hecho, en ninguna de las reconstrucciones de Cupressaceae $s . l$. fósiles se ha relacionado un morfogénero de leño. Con respecto a la similitud morfológica y la conexión orgánica, no fueron evidencias halladas en este caso, como consecuencia del tipo de fosilización de los restos. Considerando los criterios de Anderson \& Anderson (1985), se puede decir que esta reconstrucción tiene un grado de confiabilidad bueno (2).

Las características morfoanatómicas de los fósiles involucrados, permitieron inferir que la conífera reconstruida habría sido un árbol de $13 \mathrm{~m}$ de altura, muy ramificado, con ramas de anteúltimo orden con hojas escuamiformes y ramas de último orden alternas, con hojas sésiles, uninervias, lineares a aciculares distribuidas helicoidalmente.

\section{EI rol de las coníferas en los ecosistemas triásicos}

Los fósiles de la Formación Cortaderita indican que en el Triásico Medio, dos tipos de coníferas estaban presentes: las coníferas de transición Voltziaceae y coníferas modernas, probablemente relacionadas a las Cupressaceae s.l. Como de las primeras, sólo se ha encontrado impresiones-compresiones de hojas, no se puede asegurar que las Voltziaceae hayan sido constituyentes importantes de los bosques permineralizados de la Formación Cortaderita. Por otro lado, se registran troncos in situ e impresiones-compresiones vinculadas a las Cupressaceae s.l., se puede inferir que han sido componentes arbóreos de dichos bosques. Dado que su abundancia es mucho menor a los otros representantes arbóreos de estas paleocomunidades, i.e. las Corystospermales, habrían sido elementos subordinados. Esto se condice con el registro global del orden Pinales, que indica que las coníferas modernas durante el Triásico eran elementos poco abundantes de las paleocomunidades arbóreas, generalmente superados en importancia por las corystospermas y las coníferas de transición. Recién para finales del Triásico Tardío, esta situación se revierte, y ya para el Jurásico Temprano los integrantes del Orden Pinales se transforman en los árboles dominantes de los bosques a nivel mundial.

Particularmente, el registro fósil de estructuras reproductivas sugiere que la familia Cupressaceae s.l. se origina durante el Triásico (Lemoigne, 1967; Miller, 1982; Yao et al., 1997), pero los fósiles de este período son escasos, aislados y, en muchas oportunidades, discutibles (Lemoigne, 1967; Bock, 1969). Para el Jurásico los registros son más abundantes, y se conocen para ambos hemisferios por lo que podría decirse que la familia se estableció en ese momento. Austrohamia minuta del Jurásico Inferior de la Formación Cañadón Asfalto (Provincia de Chubut, Argentina) es, probablemente, el fósil más completo e indiscutible de Cupressaceae s.l., puesto que se han encontrado en conexión ramas foliosas de diferentes órdenes con conos micro y megasporangiados (Escapa et al., 2008), y a su vez se ha encontrado un bosque petrificado in situ en la misma localidad que posiblemente represente la misma entidad biológica (obs. pers.). Para el Jurásico Medio a Tardío, han sido descriptos Elatides williamsonii (Lindley \& Hutton) Nathorst basado en órganos reproductivos de la flora de Yorkshire (Harris, 1943, 1979); Sewardiodendron laxum de China, que incluye conos megasporangiados en conexión orgánica con ramas foliosas (Yao et al., 1989); y Hughmillerites Rothwell, Stockey, Mapes \& Hilton, 2011, de Escocia, representado por conos megasporangiados permineralizados.

Es interesante destacar que todos los registros jurásicos de estructuras reproductivas son asignables a las Taxodiaceae, esto es, a las basales Cupressaceae s.l.; por lo que hasta el momento el registro fósil apoya las hipótesis filogenéticas basadas en taxones vivientes (Gadek et al., 2000; Farjon \& Ortiz Garcia, 2003).

El registro triásico y jurásico de leños permineralizados del tipo cupresoide es mucho más numeroso y diverso que el de las estructuras reproductivas, lo que probablemente responde a causas tafonómicas. Para el Mesozoico temprano se han citado a los morfogéneros Sequoioxylon Torrey, Taxodioxylon Hartig, Protaxodioxylon Bamford \& Philippe, Oguraxylon Nishida, Protocallitrixylon Yamazaki \& Tsunada, Cupressinoxylon Göppert, Tetraclinoxylon Grambast; Widdringtonoxylon Penny, Juniperoxylon Houlbert, Protocupressinoxylon Eckhold, y Protojuniperoxylon Eckhold, entre otros. Los más antiguos son los leños asignados a "Cupressinoxylon" y "Juniperoxylon" (Francia, Lemoigne, 1967), Protojuniperoxylon ischigualastense (Argentina, Bonetti, 1966) y Protochamaecyparixylon klitzschii Giraud in Giraud \& Hankel 1985 (Tanzania y Chile, Lutz et al., 1999) del Triásico Superior. En el caso de los ejemplares franceses, las descripciones realizadas son insuficientes para certificar la determinación de los mismos como Cupressaceae s.l. En el caso, de los especímenes gondwánicos, para algunos autores, las asignaciones a esta familia son refutables hasta no encontrarse una estructura reproductiva que confirme sin dudas la presencia del grupo durante el Triásico.

\section{CONCLUSIONES}

Los bosques del Triásico Medio de la Formación Cortaderita estaban dominados por las corystospermas, siendo las coníferas un elemento subordinado de su estrato arbóreo.

De los grupos desarrollados en este trabajo, es la primera cita de una Cupressaceae s.l. para el Triásico Medio de la Argentina y Sudamérica. La reconstrucción realizada de esta planta fósil abarca hojas de la especie Elatocladus planus y leños de la nueva especie Cupressinoxylon zamunerae.

Con esta nueva información, se puede decir que la diversidad de coníferas en el Triásico Medio probablemente era mayor de lo interpretado hasta ahora. 


\section{AGRADECIMIENTOS}

El trabajo se realizó y se financió en el marco de la Universidad Nacional de La Plata (Proyecto N686), y de la Agencia Nacional de Promoción Científica y Tecnológica (PICT 363 y 2450). Los autores desean expresar sus agradecimientos a los revisores y editores, cuyos comentarios han enriquecido de manera significativa el manuscrito original.

\section{REFERENCIAS}

Anderson, H.M. 1978. Podozamites and associated cones and scales from the Upper Triassic Molteno Formation, Karoo Basin, South Africa. Palaeontologia Africana, 21:57-77.

Anderson, J.M. \& Anderson, H.M. 1985. Palaeoflora of Southern Africa: Prodromus of South African Megafloras Devonian to Lower Cretaceous. Rotterdam, A.A. Balkema, 423 p.

Anderson, J.M. \& Anderson, H.M. 1989. Palaeoflora of Southern Africa Molteno Formation (Triassic). Vol. 2: Gymnosperms (excluding Dicroidium). Rotterdam, A. A. Balkema, 567 p.

Anderson, J.M. \& Anderson, H.M. 2003. Heyday of gymnosperms: systematics and biodiversity of the Late Triassic Molteno fructifications. Strelitzia, 15:1-398.

Arce, F.E. \& Lutz, A.I. 2010. Fructificaciones de la Formación Los Rastros, Triásico Superior, Provincia de San Juan, Argentina. Revista Mexicana de Ciencias Geológicas, 27:32-42.

Archangelsky, S. 1966. New gymnosperms from the Ticó Flora, Santa Cruz Province, Argentina. Bulletin of the British Museum (Natural History). Geology, 13:261-295.

Archangelsky, S. 1970. Fundamentos de Paleobotánica. Facultad de Ciencias Naturales y Museo, Universidad Nacional de la Plata, Serie técnica y Didáctica 10, 347 p.

Archangelsky, S. \& Del Fueyo, G.M. 2010. Endemism of Early Cretaceous Conifers in Western Gondwana. In: C.T. Gee (ed.) Plants in Mesozoic Time: Innovations, Phylogeny, Ecosystems (Ted Delevoryas festschrift), Indiana University Press, p. 247-268.

Arnold, C.A. 1947. An introduction to paleobotany. Nueva York, McGraw-Hill, 433 p.

Artabe, A.E.; Morel, E.M. \& Spalletti, L.A. 2001. Paleoecología de las floras triásicas argentinas. In: A.E.Artabe; E.M. Morel \& A.B. Zamuner (eds.) El Sistema Triásico de Argentina. La Plata, Fundación Museo de La Plata "Francisco Pascasio Moreno", p.199-225.

Artabe, A.E.; Morel, E.M. \& Spalletti, L.A. 2003. Caracterización de las provincias fitogeográficas triásicas del Gondwana extratropical. Ameghiniana, 40:387-405.

Artabe, A.E.; Morel, E.M. \& Ganuza, D.G. 2007. Las floras triásicas de la Argentina. In: S. Archangelsky; T. Sánchez \& E.P. Tonni (eds.) Asociación Paleontológica Argentina Publicación Especial 11 Ameghiniana $50^{\circ}$ Aniversario, Buenos Aires, p.75-86.

Axsmith, B.J.; Taylor, T.N. \& Taylor, E.L. 1998. Anatomically preserved leaves of the conifer Notophytum krauselii (Podocarpaceae) from the Triassic of Antarctica. American Journal of Botany, 85:704-713. doi:10.2307/2446541.

Baldoni, A.M. 1980a. Plantas fósiles jurásicas de una nueva localidad en la provincia de Neuquén. Ameghiniana, 17:255-272.

Baldoni, A.M. 1980b. Nota sobre una nueva especie de Elatocladus (?) (Coniferae) de la formación Springhill, límite JurásicoCretácico, provincia de Santa Cruz. Ameghiniana, 17:373-378.

Baldoni, A.M. 1980c. Tafoflora jurásica de la zona de Picún Leufú, provincia del Neuquén. Ameghiniana, 17:243-254.
Bamford, M.; Ziljstra, G. \& Philippe, M. 2002. Proposal to conserve the name Cupressinoxylon Göppert (Fossil, Gymnospermae, Coniferales) against Retinodendron Zenker (Fossil, Gymnospermae, Coniferales), with a conserved type. Taxon, 51:205-206. doi:10.2307/1554991

Barredo, S.P. \& Ramos, V.A. 1997. Los depósitos de Rincón Blanco (Precordillera de San Juan): un rift triásico. In: JORNADAS SOBRE GEOLOGÍA DE PRECORDILLERA, 2, 1997. Actas, San Juan, 1, p.130-135.

Berry, E.W. 1924. Mesozoic plants from Patagonia. American Journal of Science, 5:473-482.

Bhardwaj, D. 1953. Jurassic woods from the Rajmahal Hills, Bihar. The Palaeobotanist, 2:59-70.

Bock, W. 1969. The American Triassic flora and global distribution. North Wales, Geological Center Research Series, 406 p.

Bodnar, J. 2008. Rhexoxylon cortaderitaense (Menéndez) comb. nov., a species of permineralized stems newly assigned to the Corystospermaceae, from the Triassic of Argentina. Alcheringa, 32:171-190. doi:10.1080/03115510801928338

Bodnar, J. 2010. La paleoflora triásica de la Formación Cortaderita en la quebrada homónima, Cuenca de Barreal - Calingasta, provincia de San Juan, Argentina, Tesis Doctoral, Facultad de Ciencias Naturales y Museo, Universidad Nacional de La Plata, 283 p.

Bodnar, J. \& Artabe, A.E. 2007. Estudio sistemático y paleodendrológico del leño de una Cupressaceae triásica de la Formación Ischigualasto, provincia de San Juan, Argentina. Ameghiniana, 44:303-319.

Bomfleur, B.; Decombeix, A-L.; Escapa, I.H.; Schwendemann, A.B. \& Axsmith, B. 2013. Whole-plant concept and environment reconstruction of a Telemachus conifer (Voltziales) from the Triassic of Antarctica. International Journal of Plant Science, 174:425-444. doi:10.1086/668686

Bonetti, M.I.R. 1963. Contribución al conocimiento de la flora fósil de Barreal, departamento de Calingasta (provincia de San Juan). Tesis Doctoral, Facultad de Ciencias Exactas y Naturales, Universidad de Buenos Aires, 260 p.

Bonetti, M.I.R. 1966. Protojuniperoxylon ischigualastensis sp. nov. del Triásico de Ischigualasto (San Juan). Ameghiniana, 4:211-218

Bonetti, M.I.R. 1968. Las especies del género Pseudoctenis en la flora triásica de Barreal (San Juan). Ameghiniana, 5:433-446.

Bonetti, M.I.R. 1972. Las "Bennettitales" de la flora Triásica de Barreal (San Juan). Revista del Museo Argentino de Ciencias Naturales Bernardino Rivadavia, 1:307-322.

Bose, M.N. 1961. Leaf-cuticle and other plant microfossils from the Mesozoic rocks of Andøya, Norway. The Paleobotanist, 8:1-7.

Bose, M.N. \& Banerji, J. 1984. The fossil flora of Kachchh 1 -Mesozoic megafossils. The Palaeobotanist, 33:1-189.

Bose, M.N. \& Mahaeshwari, H. 1974. Mesozoic conifers. In: K. Surange; R.N. Lakhanpal \& D.Bhardwaj (eds.) Aspects and Appraisal of Indian Palaeobotany, Lucknow, Birbal Sahni Institute of Palaeobotany, p.212-223.

Boureau, E. 1956. Anatomie Végétale: L'appareil végétatif des Phanérogames, Tome Second. París, Presses Universitaires de France, $524 \mathrm{p}$.

Boutelje, J.B. 1955. The wood anatomy of Libocedrus Endl., s. lat., and Fitzroya J. D. Hook. Acta Horti Bergiani, 17:177-216.

Braun, C.F.W. 1843. Beiträge zur Urgeschichte der Pflanzen. Münster's Beitrage zur Petrifacten-Kunde, 6:1-46.

Caminos, R.; Zamuner, A.B.; Limarino, C.O. \& Fauqué, L. 1995. Triásico Superior fosilífero en la Precordillera riojana. Revista de la Asociación Paleontológica Argentina, 50:262-265. 
Cantino, P.D. \& de Queiroz, K. 2006. International Code of Phylogenetic Nomenclature, Version 3a. Part 1: Clade Names. International Society for Phylogenetic Nomenclature, $83 \mathrm{p}$. http://www.ohiou.edu/phylocode/PhyloCode3a.pdf.

Cantino, P.D.; Doyle, J.A.; Graham, S.W.; Judd, W.S.; Olmstead, R.G.; Soltis, D.E.; Soltis, P.S. \& Donoghue, M.J. 2007. Towards a phylogenetic nomenclature of Tracheophyta. Taxon, 56:822846. doi:10.2307/25065865

Conwentz, H. 1885. Sobre algunos árboles fósiles del río Negro. Boletín de la Academia Nacional de Ciencias, 7:435-502.

Christenhusz, M.J.M.; Reveal, J.L.; Farjon, A.; Gardner, M.F.; Mill, R.R. \& Chase, M.W. 2011. A new classification and linear sequence of extant gymnosperms. Phytotaxa, 19:55-70. doi: $10138 / 28041$

Crisafulli, A. \& Herbst, R. 2010. Leños gimnospérmicos de la Formación Llantenes (Triásico Superior) provincia de Mendoza. GAEA, Journal of Geosciences, 6:14-20. doi:10.4013/ gaea.2010.61.03

Crisafulli, A. \& Herbst, R. 2011. La Flora Triásica del Grupo El Tranquilo, provincia de Santa Cruz (Patagonia): Leños Fósiles. Ameghiniana, 4:275-288. doi:10.5710/AMGH.v48i3(310)

Cronquist, A., Takhtajan, A. \& Zimmermann, W. 1966. On the higher taxa of Embryobionta. Taxon, 14:129-134. doi:10.2307/1217531

Cuerda, A. J. 1945. Estratigrafía y tectónica al este de Barreal, provincia de San Juan. Tesis Doctoral, Facultad de Ciencias Naturales y Museo, Universidad Nacional de La Plata, $44 \mathrm{p}$.

De Jersey, N.J. 1962. Triassic spores and pollen grains from the Ipswich Coalfield. Geological Survey of Queensland, 307:1-18.

De Magistris, A.A. 1997. Anatomía de la madera de las especies de Cupressus (Cupressaceae) cultivadas en la Argentina. Boletín de la Sociedad Argentina de Botánica, 33:91-105.

Decombeix, A-L.; Taylor, E.L. \& Taylor, T.N. 2011. Root suckering in a Triassic conifer from Antarctica: paleoecological and evolutionary implications. American Journal of Botany, 98:1222-1225. doi:10.3732/ajb.1100028

Del Fueyo, G.M., Archangelsky, S. \& Taylor, T.N. 1990. Una nueva Podocarpácea fértil (Coniferal) del Cretácico inferior de Patagonia Ameghiniana, 27:63-73

Dolianiti, E. 1948. A paleobotanica no Brazil. Rio de Janeiro, Departamento Nacional da Produção Mineral, Divisão de Geologia e Mineralogia, p. 1-87. (Boletim 123).

Du Toit, A.L. 1927. A geological comparison of South America with South Africa. Carnegie Institution, 381:1-150.

Eckenwalder, J.E. 1976. Re-evaluation of Cupressaceae and Taxodiaceae: a proposed merger. Madroño, 23:237-256.

Eckenwalder, J.E. 2009. Conifers of the world: the complete reference. Portland, Timber Press, $720 \mathrm{p}$.

Eckhold, W. 1923 (1921). Die Hoftüpfel bei rezenten und fossilen Coniferen. Jahrbuch der Preußischen Geologischen Landesanstalt zu Berlin, 42:472-505.

Eggerton, V. 2011. The Geology, Paleontology and Paleoecology of the Cerro Fortaleza Formation, Patagonia (Argentina). Thesis, Faculty of Drexel University. 253p.

Endo, S. 1951. A record of Sequoia from the Jurassic of Manchuria. Botanical Gazette, 113: 228-230.

Escapa, I.H.; Cúneo, N.R. \& Axsmith, B. 2008. A new genus of the Cupressaceae (sensu lato) from the Jurassic of Patagonia: implications for conifer megasporangiate cone homologies. Review of Palaeobotany and Palynology, 151:110-122. doi:10.1016/j.revpalbo.2008.03.002

Escapa, I.H.; Decombeix, A-L.; Taylor, E.L. \& Taylor, T.N. 2010. Evolution and relationships of the conifer seed cone Telemachus:
Evidence from the Triassic of Antarctica. International Journal of Plant Sciences, 171:560-573. doi:10.1086/651948

Fahn, A. 1990. Plant anatomy. Oxford, Pergamon Press, 588 p.

Falcon-Lang, H.J. 2003. Growth interruptions in silicified conifer woods from the Upper Cretaceous Two Medicine Formation, Montana, USA: implications for palaeoclimate and dinosaur palaeoecology. Palaeogeography, Palaeoecology, Palaeoclimatology, 199:299-314. doi:10.1016/S00310182(03)00539-X

Falcon-Lang, H.J. \& Cantrill, D.J. 2001. Gymnosperm woods from the Cretaceous (mid-Aptian) Cerro Negro Formation, Byers Peninsula, Livingston Island, Antarctica: the arborescent vegetation of a volcanic arc. Cretaceous Research, 22:277-293. doi:10.1006/cres.2001.0259

Farjon, A., 2005. A Monograph of Cupressaceae and Sciadopitys. Londres, Kew Publishing, 648 p.

Farjon, A. \& Ortiz García, S. 2003. Cone andovule development in Cunninghamia and Taiwania (Cupressaceae sensu lato) and its significance for conifer evolution. American Journal of Botany, 90:8-16. doi:10.3732/ajb.90.1.8

Florin, R. 1922. On the geological history of the Sciadopitinae. Svensk Botanisk Tidskrift 16: 260-270.

Florin, R. 1940. The Tertiary fossil conifers of South Chile and their phytogeographical significance with a review ofthe fossil conifers of southern lands. Kiingliga Svenska Vetenskapakadiems Handlingar, 19:1-107.

Florin, R. 1958. On Jurassic taxads and conifers from northwestern Europe and eastern Greenland. Acta Horti Bergiani, 17:257-402.

Font Quer, P. 1963. Diccionario de Botánica. $2^{a}$ reimpresión. Barcelona, Editorial Labor, 1244 p.

Font Quer, P. 1982. Diccionario de Botánica. $8^{a}$ reimpresión. Barcelona, Editorial Labor, 1244 p.

Fralish, J.S. \& Franklin, S.B. 2002. Taxonomy and ecology of woody plants in North American forests (excluding Mexico and Subtropical Florida). Nueva York, John Wiley \& Sons, 612 p.

Frenguelli, J. 1944. Contribuciones al conocimiento de la flora del Gondwana superior en la Argentina. Elatocladus australis n. sp. Notas del Museo de La Plata (Paleontología), 9:543-548.

Gadek, P.A.; Alpers, D.L.; Heslewood, M.M. \& Quinn, C.J. 2000. Relationships within Cupressaceae sensu lato: a combined morphological and molecular approach. American Journal of Botany, 87:1044-1057. doi:10.2307/2657004

Gee, C.T. 1989a. Revision of the Late Jurassic/Early Cretaceous flora from Hope Bay, Antarctica. Palaeontographica B, 213:149-214.

Gee, C.T. 1989b. Permian Glossopteris and Jurassic Elatocladus megafossil floras from the English Coast, eastern Ellsworth Land, Antarctica. Antarctic Science, 1:35-44.

Giraud, B \& Hankel, O. 1985. Bois fossiles des dépôts du Karoo du Bassin du Luwegu (Tanzanie Méridionale). Annales de Paléontologie, 71:159-185.

Gnaedinger, S. \& Herbst, R. 2009. Primer registro de maderas gimnospérmicas de la Formación Roca Blanca (Jurásico Inferior), provincia de Santa Cruz, Argentina. Ameghiniana, 46:59-71.

Göppert, J.H.R. 1850. Monographie der fossilen Coniferen. Leiden, Arnz \& Comp., 286 p.

Gorozhankin, I.N., 1904. Lektsii po morfologii i sistematike archegonialnykh rastenij. II, Pteridophyta, I, Archispermae. Moscú, A.I. Mamontov, p.73-93.

Govil, C.M. 2007. Gymnosperms: extinct and extant. Dehli, Krishna Prakashan Media, 332 p. 
Grauvogel-Stamm, L. 1978. La flore du Grès a Voltzia (Buntsandstein Supérieur) des Vosges du Nord (France), morphologie, anatomie, interprétations phylogénique et paléogéographique. Sciences géologiques, Mémoire 50:1-225.

Greguss, P. 1955. Identification of living gymnosperms on the basis of xylotomy. Budapest, Akádemiai Kiadó, 263 p.

Greguss, P. 1968. Xylotomy of the living cycads with a description of their leaves and epidermis. Budapest, Akademiai Kiadó, 260 p.

Groeber, P.F.C. \& Stipanicic, P.N. 1953. Triásico.In: Groeber, P.F.C. (ed.) Mesozoico. Buenos Aires, Sociedad Argentina de Estudios Geográficos, p. 13-141 (Geografia de la República Argentina 2).

Halle, T.G. 1913. The mesozoic flora of Graham Land. Wissenschaftliche Ergebnisse Schwedische Südpol Expedition 1901-1903, 3:1-123.

Harris, T.M. 1943. The fossil conifer Elatides williamsoni. Annals of Botany, 7:325-339.

Harris, T.M. 1979. The Yorkshire Jurassic Flora. V. Coniferales. Londres, British Museum (Natural History), 167 p.

Heer, O. 1876. Beiträge zur Jura-Flora Ostsibiriens und des Amurlandes. Mémoires de L'Acadamie Imperiale des Sciences de St. Petesburg, VII Serie, 22:1-58.

Herbst, R. \& Anzótegui, L. 1968. Nuevas plantas de la flora del Jurásico medio (Matildense) de Taquetrén, provincia de Chubut. Ameghiniana, 5:183-190.

Herbst, R.; Brea, M.; Crisafulli, A.; Gnaedinger, S.; Lutz, A.I. \& Martinez, L. 2007. La Paleoxilología en la Argentina. Historia y Desarrollo. Asociación Paleontológica Argentina, 11:57-71.

Hill, D.; Playford, G. \& Woods, J.T. 1966. Jurassic fossils of Queensland. Brisbane, Queensland Palaeontographical Society, $32 \mathrm{p}$.

IAWA Comittee. 2004. International Association of Wood Anatomists list of microscopic features for softwood identification. IAWA Journal, 25:1-70.

Jain, R. \& Delevoryas, T. 1967. A Middle Triassic Flora from the Cacheuta Formation, Minas de Petróleo, Argentina. Palaeontology, 10:564-589.

Jaworski, E. 1915. Beiträge zur Kenntnis des Jura in Süd-Amerika, Teil 2. Neues Jahrbuch für Mineralogie, Geologie und Paläontologie, 40:364-456.

Jongmans, W.J. \& Dijkstra, S.J. 1972. Fossilium Catalogus II: Plantae: Pars 81: Gymnospermae (Ginkgophyta Et Coniferae) III Coniferites-Dadoxylon (Fossilium Catalogus Plantae), 's-Gravenhage, Dr. W. Junk BV, 110 p.

Kräusel, R. 1920. Nachträge zur Tertiärflora Schlesiens II. Braunkohlenhölzer. Jahrbuch der Preußischen Geologischen Landesanstalt, 39:418-460.

Kräusel, R. 1924. Beiträge zur Kenntnis der fossilen Flora Südamerikas 1. Fossile Hölzer aus Patagonien und benachbarten Gebieten. Arkiv för Botanik, 19:1-36.

Kräusel, R. 1949. Die fossilen Koniferenhölzer (unter Ausschlu $\beta$ von Araucarioxylon Krauß.), II. Kritische Untersuchungen zur Diagnostik lebender und fossiler Koniferen-Hölzer. Palaeontographica B, 89:81-203.

Kumarasamy, D. \& Jeyasingh, D.E.P. 2004. A new species of Cupressinoxylon Göeppert from the. Sriperumbudur Formation, India. Phytomorphology, 54:97-104.

Lemoigne, Y. 1967. Paléoflore à Cupressales dans le Trias-Rhétien du Cotentin. Comptes Rendus Hebdomadaires des Séances de l'Académie des Sciences Série D, 264:715-718.

López Gamundí, O. 1994. Facies distribution in an asymmetric halfgraben: the northern Cuyo Basin (Triassic), western Argentina In: INTERNATIONAL SEDIMENTOLOGICAL CONGRESS, 14, 1994. Abstracts, Recife, p. 6-7.
Lutz, H.J. 1930. A new species of Cupressinoxylon (Göppert) Gothan from the Jurassic of South Dakota. Botanical Gazette, 90:92-107.

Lutz, A.I. \& Herbst, R. 1992. Una nueva especie de Rhexoxylon del Triásico de Barreal, San Juan Argentina. Asociación Paleontológica Argentina, 2:73-76.

Lutz, A.I.; Crisafulli, A. \& Herbst, R. 1999. Gymnospermous woods from the Upper Triassic of Northern Chile. The Palaeobotanist, 48:31-38.

Martínez, L.C.A. 2010. Estudios xilológicos en el Cretácico de la Cuenca Neuquina, provincia de Neuquén, Argentina. Tesis Doctoral, Facultad de Ciencias Naturales y Museo, Universidad Nacional de La Plata, 238 p.

McLoughlin, S. \&, Drinnan, A.N. 1995. A Middle Jurassic flora from the Walloon Coal Measures, Mutdapilly, Queensland, Australia. Memoirs of the Queensland Museum, 38:257-272.

McNeill, J.; Barrie, F.R.; Buck, W.R.; Demoulin, V.; Greuter, W.; Hawksworth, D.L.; Herendeen, P.S.; Knapp, S.; Marhold, K.; Prado, J.; Prud'homme Van Reine, W.F.; Smith, G.F.; Wiersema, J.H. \& Turland, N.J. 2012. International Code of Nomenclature for algae, fungi and plants (Melbourne Code) adopted by the Eighteenth International Botanical Congress Melbourne, Australia, July 2011. Koenigstein, Koeltz Scientific Books, XXX+240 p (Regnum Vegetabile 154).

Menéndez, C.A. 1951. La flora mesozoica de la Formación Llantenes (provincia de Mendoza). Revista del Instituto Nacional de Investigaciones en Ciencias Naturales (Botánica), 2:147-261.

Menéndez, C.A. 1956. Protophyllocladoxylon cortaderitaensis $\mathrm{sp}$. nov. Tronco fósil del Triásico de Barreal (provincia de San Juan) Revista de la Asociación Geológica Argentina, 11:273-280.

Menéndez, C.A. 1969. Die Fossilen Floren Südamerikas. In: E.J. Fittkav; J. Illies; H. Klinge; G.H. Schwabe \& H. Sioli. (eds.) Biogeography and Ecology in South America 2, 's-Gravenhage, Dr. W. Junk BV, p. 519-561.

Mésigos, M.G. 1953. El Paleozoico Superior de Barreal y su continuación austral, Sierra de Barreal, Provincia de San Juan. Revista de la Asociación Geológica Argentina, 8:65-109.

Meyer-Berthaud, B. \& Taylor, T.N. 1991. A probable conifer with podocarpaceous affinities from the Triassic of Antarctica. Review of Palaeobotany and Palynology, 67:179-198. doi:10.1016/0034-6667(91)90041-Z

Miller, C.N. 1982. Current status of Paleozoic and Mesozoic conifers. Review of Palaeobotany and Palynology, 37:99-114. doi:10.1016/0034-6667(82)90039-2

Morel, E. M.; Artabe, A.E.; Ganuza, D. \& Zúñiga, A. 2011. La Paleoflora Triásica del Cerro Cacheuta, provincia de Mendoza. Petriellales, Cycadales, Ginkgoales, Voltziales, Coniferales, Gnetales y Gimnospermas incertae sedis. Ameghiniana, 48:520540. doi:10.5710/AMGH.v48i4(376)

Morel, E.M.; Artabe, A.E.; Zavattieri, A.M. \& Bonaparte, J. 2001 Cronología del Triásico de Argentina. In: A.E.Artabe; E.M. Morel \& A.B. Zamuner (eds.) El Sistema Triásico de Argentina. La Plata, Fundación Museo de La Plata "Francisco Pascasio Moreno", p.. 227-253.

Morgans, H.S.; Hesselbo, S.P. \& Spicer, R.A. 1999. The Seasonal Climate of the Early-Middle Jurassic, Cleveland Basin, England: Palaios, 14:261-272. doi:10.2307/3515438

Niklas, K.J. 1994a. Plant allometry: the scaling of form and process. Chicago, University of Chicago Press, 412 p.

Niklas, K.J. 1994b. The allometry of safety-factors for plant height. American Journal of Botany, 81:345-351. doi:10.2307/2445462

Niklas, K.J. 1994c. Predicting the height of fossil plant remains: an allometric approach to an old problem. American Journal of Botany, 81:1235-1242. doi:10.2307/2445398 
Nishida, M. 1984a. The anatomy and affinities of the petrified plants from the Tertiary of Chile I. In: M. Nishida (ed.) Contributions to the Botany in the Andes I, Tokyo, Academia Scientific Book Inc, p. 81-85.

Nishida, M. 1984b. The anatomy and affinities of the petrified plants from the Tertiary of Chile III. Petrified woods from Mocha Island, Central Chile. In: M. Nishida (ed.) Contributions to the Botany in the Andes I, Tokyo, Academia Scientific Book Inc, p. 96-110.

Nishida, M. \& Nishida, H. 1988. Preliminary studies on the petrified plants from the Creto-Tertiary of Chile. In: Nishida, M. (ed.) A report of the botanical survey to Bolivia and southern Chile (1986-87), p. 26-28.

Oliveira, E.P. de. 1936. Madeiras petrificadas do planalto dos Parecis. Rio de Janeiro, Departamento Nacional de Produção Mineral, Divisão de Geologia e Mineralogia, 14 p. (Notas Preliminares e Estudos 3).

Patel, R.N. 1968. Wood anatomy of Cupressaceae and Araucariaceae indigenous to New Zealand. New Zealand Journal of Botany, 6:9-18.

Peirce, A.S. 1937. Systematic anatomy of the woods of the Cupressaceae. Tropical Woods, 49:5-21.

Philippe, M. \& Bamford, M.K. 2008. A key to morphogenera used for Mesozoic conifer-like woods. Review of Palaeobotany and Palynology, 148:184-207. doi:10.1016/j.revpalbo.2007.09.004

Philippe, M.; Bamford, M.; McLoughlin, S.; Alves, L.S.R.; Falcon-Lang, H.J.; Gnaedinger, S.; Ottone, E.G.; Pole, M.; Rajanikanth, A.; Shoemaker, R.E.; Torres, T. \& Zamuner, A. 2004. Biogeographic analysis of Jurassic-Early Cretaceous wood assemblages from Gondwana. Review of Palaeobotany and Palynology, 129:141-173. doi:10.1016/j.revpalbo.2004.01.005

Poole, I.; Hunt, R.J. \& Cantrill, D.J. 2001. A Fossil Wood Flora from King George Island: Ecological Implications for an Antarctic Eocene Vegetation. Annals of Botany, 88:33-54. doi:10.1006/ anbo.2001.1425

Prakash, U. \& Srivastava, S.K. 1961. On a gymnospermous fossil woods from Sitapuri District Dhar in Madhya Pradesh. The Palaeobotanist, 10:10-17.

Pujana, R.R. 2008. Estudio paleoxilológico del Paleógeno de Patagonia austral (Formaciones Río Leona, Río Guillermo y Río Turbio) y Antártida (Formación La Meseta), Tesis Doctoral, Facultad de Ciencias Exactas y Naturales, Universidad de Buenos Aires, $182 \mathrm{p}$.

Rajanikanth, A. \& Sukh-Dev, A. 1989. The Kota Formation: fossil flora and Stratigraphy. Geophytology, 19:52-64.

Ram-Awatar \& Rajanikanth, A. 2007. Triassic conifer wood from the Tiki Formation, South Rewa Basin, Madhya Pradesh, India. The Palaeobotanist, 56:127-132.

Retallack, G.J. 1981. Middle Triassic megafossil plants from Long Gully, near Otematata, north Otago, New Zealand. Journal of the Royal Society of New Zealand, 11:167-200.

Reveal, J.L. 2012. Indices Nominum Supragenericorum Plantarum Vascularium. Alphabetical Listing by Genera of Validly Published Suprageneric Names. http://www.plantsystematics. org/reveal/pbio/fam/allspgnames.html

Roig, F.A. 1992. Comparative wood anatomy of Southern South American Cupressaceae. IAWA Bulletin, 13:151-162.

Rothwell, G.W.; Mapes, G. \& Hernandez-Castillo, G.R. 2005. Hanskerpia gen. nov. and phylogenetic relationships among the most ancient conifers (Voltziales). Taxon, 54:733-750. doi: $10.2307 / 25065430$

Rothwell, G.W.; Stockey, R.A.; Mapes, G. \& Hilton, J. 2011. Structure and relationships of the Jurassic conifer seed cone
Hughmillerites judii gen. et sp. nov. implications for the early evolution of cupressaceae. Review of Palaeobotany and Palynology, 164:45-59. doi:10.1016/j.revpalbo.2010.11.004

Ru-feng, W, Yu-fei, W \& Yong-zhe, C. 1996. Cupressinoxylon jiayinense, a new species of the Late Cretaceous from Heilongjiang Province, China. IAWA Journal, 17:319-326.

Seward, A.C. 1919. Fossil Plants, Volume IV. Ginkgoales, Coniferales, Gnetales. Cambridge, Cambridge University Press, 543 p.

Spalletti, L.A. 2001a. Modelo de sedimentación fluvial y lacustre en el margen pasivo de un hemigraben: el Triásico de la Precordillera occidental de San Juan, República Argentina. Revista de la Asociación Geológica Argentina, 56:189-210.

Spalletti, L.A. 2001b. Evolución de las cuencas sedimentarias. In: A.E. Artabe; E.M. Morel \& A.B. Zamuner (eds.) El Sistema Triásico de Argentina. La Plata, Fundación Museo de La Plata "Francisco Pascasio Moreno", p.81-101.

Spalletti, L.A.; Arrondo, O.G.; Morel, E.M. \& Ganuza, D.G. 1991. Evidencias sobre la edad triásica de la Formación Lapa en la región de Chacaico, Provincia del Neuquén. Revista de la Asociación Geológica Argentina, 46:167-172.

Stewart, W.N. \& Rothwell, G.W. 1993. Paleobotany and the Evolution of Plants. Cambridge, Cambridge University Press, 521 p.

Stipanicic, P.N. 1972. Cuenca triásica de Barreal. In: A.F. Leanza (ed.) Geología Regional Argentina, Córdoba, Academia Nacional de Ciencias, p. 537-566.

Stipanicic, P.N. 1979. El Triásico del valle del Río de Los Patos (provincia de San Juan). In: J.C.M. Turner (ed.), Geología Regional Argentina, Córdoba, Academia Nacional de Ciencias, p. 695-744.

Stipanicic, P.N. 1983. The Triassic of Argentina and Chile. In: M. Moullade \& A.E.M. Nairim (eds) The Phanerozoic geology of the World. II, The Mesozoic, Amsterdam, Elsevier, p. 181-199.

Taylor, T.N.;Taylor, E.L. \& Krings, M. 2009. Paleobotany, The Biology and Evolution of Fossil Plants, Second Edition, Amsterdam, Academic Press, 1230 p.

Torres, T. \& Philippe, M. 2002. Dos nuevas especies de Agathoxylon y Baieroxylon del Jurásico Inferior de La Ligua, Chile: datos paleoxilológicos en América del Sur. Revista Geológica de Chile, 29:151-165. doi:10.4067/S0716-02082002000200001

Torres, T.; Marenssi, S. \& Santillana, S. 1994. Maderas fósiles de la isla Seymour, Formación La Meseta, Antártica. Serie Científica INACH, 44:17-38.

Townrow, J.A. 1967. On Rissikia and Mataia podocarpaceous conifers from the lower Mesozoic of southern lands. Papers and Proceedings of the Royal Society of Tasmania, 101:103-136.

Tutin, T.G. (ed.) 1993. Flora Europaea, Volumen 1: Psilotaceae to Platanaceae. Cambridge, Cambridge University Press, 629 p.

Vaudois, N. \& Privé, C. 1971. Révision des bois fossiles de Cupressaceae. Palaeontographica B, 134:61-86.

Vozenin-Serra, C. \& Grant-Mackie, J. 1996. Les bois noriens des terrains Murihiku -Nouvelle Zélande. Palaeontographica B, 241:99-125.

Walkom, A.B. 1919. Mesozoic floras of Queensland parts III and IV. The floras of the Burrum and Styx River series. Brisbane, Geological Survey of Queensland, 76 p. (Publication 263).

White, M.E. 1981. Revision of the Talbragar FishBed Flora (Jurassic) of New South Wales. Records of the Australian Museum, 33:695-721

Yao, X.; Taylor, T.N. \& Taylor, E.L. 1993. The Triassic seed cone Telemachus from Antarctica. Review of Palaeobotany and Palynology, 78:269-276. doi:10.1016/0034-6667(93)90067-5 
Yao, X.; Taylor, T.N. \& Taylor, E.L. 1997. A taxodiaceous seed cone from the Triassic of Antarctica. American Journal of Botany, 84:343-354. doi:10.2307/2446008

Yao, X., Zhou, Z. \& Zhang, B. 1989. On the occurrence of Sewardiodendron laxum Florin (Taxodiaceae) in the Middle Jurassic from Yima, Henan. Chinese Science Bulletin, 34:19801982.

Zamuner, A.B. 1992. Estudio de una tafoflora de la localidad tipo de la Formación Ischigualasto (Neotrías), Provincia de San Juan. Tesis Doctoral, Facultad de Ciencias Naturales y Museo, Universidad Nacional de La Plata, 97 p.

Zamuner, A.B. \& Artabe, A.E. 1994 Estudio de un leño fósil, Protocircoporoylon marianensis $\mathrm{n}$. sp., proveniente de las sedimentitas triásicas de la Formación Paso Flores, Provincia del Río Negro, Argentina. Ameghiniana, 31:203-207.

Zamuner, A.B.; Artabe, A.E. \& Ganuza, D.G. 1999. A new Peltasperm (Gymnospermopsida) from the Middle Triassic of Argentina. Alcheringa, 23:185-191. doi:10.1080/03115519908619515
Zamuner, A.B.; Zavattieri, A.M.; Artabe, A.E. \& Morel, E.M. 2001 Paleobotánica. In: A.E. Artabe; E.M. Morel \& A.B. Zamuner (eds) El Sistema Triásico de Argentina, La Plata Fundación Museo de La Plata "Francisco Pascasio Moreno", p.143-184.

Zavattieri, A.M. \& Rojo, L.D. 2005. Estudio microflorístico de las Formaciones Potrerillos y Cacheuta (Triásico) en el sur del cerro Cacheuta, Mendoza, Argentina. Parte 2. Ameghiniana, 42:513-534

Zhang, J-W.; D'rozario, A.; Wang, L-J.; Li, Y. \& Yao, J-X. 2012. A new species of the extinct genus Austrohamia (Cupressaceae s.1.) in the Daohugou Jurassic flora of China and its phytogeographical implications. Journal of Systematics and Evolution, 50:72-82. doi:10.1111/j.1759-6831.2011.00165.x

Received in June, 2013; accepted in January, 2015. 